\title{
Color Selectivity of Neurons in the Inferior Temporal Cortex of the Awake Macaque Monkey
}

\author{
Hidehiko Komatsu, Yoshie Ideura, Shinji Kaji, and Shigeru Yamane \\ Neuroscience Section, Electrotechnical Laboratory, Tsukuba-city, Ibaraki 305, Japan
}

\begin{abstract}
We tested the color selectivity of neurons in the inferior temporal (IT) cortex of two awake macaque monkeys. A color stimulus was presented at the center of the visual field while the animal performed a fixation task. The responses of single units to various colors were recorded and were plotted in a color space. The color space was based on the CIE (Commission Internationale de l'Eclairage) chromaticity diagram. Quantitative analysis of the color selectivity was performed using a standard set of colors that were evenly distributed in the color space. Sixty-five neurons recorded from eight guide tubes implanted in anterior part of IT cortex were tested quantitatively, and their color selectivity was statistically evaluated. Forty-six of them $(71 \%)$ were classified as color selective. Color-selective cells responded to some colors but not to others, and we called the responsive region in the color space the "color field." The location and the size of a cell's color field were largely independent of the luminance of the stimulus. About $\mathbf{8 0} \%$ of the color-selective neurons had color fields consisting of a single responsive region that were restricted in some part of the color space, and the remaining cells had more than one responsive region within the color space. Preferred hues of the color-selective neurons differed from cell to cell. The population of cells together covered nearly all of the color space. There was a tendency for more color-selective cells to be less sensitive to white and desaturated cyans. Some of the cells with color fields that consisted of more than one responsive region were more sensitive to saturation of the stimulus than to its hue. Although previous electrophysiological studies in IT cortex emphasized the pattern selectivity of the neurons, our results suggest that color is an important factor in the role that IT cortex plays in the object recognition.
\end{abstract}

Bilateral ablation of the inferior temporal (IT) cortex in primates produces a severe defect in the visual discrimination of objects. This defect occurs whether the cue for the discrimination is shape, color, brightness, orientation, or size (see Gross, 1973; Dean, 1976, 1982; Ungerleider and Mishkin, 1982; Mishkin et al., 1983). IT cortex receives strong inputs from area V4 (Kuypers et al., 1965; Rockland and Pandya, 1979; Desimone et al., 1980; Felleman et al., 1986; Boussaoud et al., 1991), which is

\footnotetext{
Received Mar. 1, 1991; revised Sept. 10, 1991; accepted Sept. 18, 1991.

We gratefully acknowledge John Maunsell and Kenji Kawano for commenting on the manuscript. We thank Kanji Katori for his help in the test of the accuracy of the colorimeter. We also thank Motoko Okui for her technical assistance.

Correspondence should be addressed to Hidehiko Komatsu, Neuroscience Section, Electrotechnical Laboratory, 1-1 Umezono, Tsukuba-city, Ibaraki 305, Japan.
}

Copyright (C) 1992 Society for Neuroscience $0270-6474 / 92 / 120408-17 \$ 05.00 / 0$ known to have both form-sensitive and color-sensitive neurons (Zeki, 1973, 1977, 1978, 1980; Schein et al., 1982; Desimune et al., 1985; M. M. Tanaka et al., 1986; Desimone and Schein, 1987; Schein and Desimone, 1990). This behavioral, anatomical, and physiological evidence suggests that IT cortex receives inputs conveying both form and color information regarding the visual stimulus.

Many attempts have been made to study neural representations of form in IT cortex. Unit recording experiments have found neurons that selectively responded to the shape of a visual stimulus (Gross et al., 1972; Rolls et al., 1977; Sato et al., 1980; Desimone et al., 1984; Baylis et al., 1985; Miyashita and Chang, 1988; Tanaka et al., 1990, 1991), and several studies have examined how neurons in IT cortex encode the shape of the stimulus (Schwartz et al., 1983; Richmond et al., 1987; Yamane et al., 1988).

On the other hand, relatively few studies have examined the color selectivity of IT neurons. The existence of IT neurons that distinguish colors has been reported in anesthetized monkeys (Gross et al., 1972; Desimone et al., 1984) and in awake monkeys that were performing a short-term memory task (Mikami and Kubota, 1980; Fuster and Jervey, 1982; Fuster, 1990). However, few colors were used in these studies, and little is known about how IT neurons represent color. In the present experiments we have explored how color is represented in IT cortex.

We have tested the responses to various luminance-matched broad-band color stimuli for each IT neuron. We found that many IT neurons responded to some colors but not to others. This supports the earlier reports that IT neurons encode color information and indicates IT cortex should be regarded not only as a form area but also as a color area. To quantify the color selectivity of each neuron, we have used the CIE (Commission Internationale de l'Eclairage) 1931 standard colorimetric system to represent the color of the stimuli used, and we mapped the responses of each neuron on the CIE color space. For the neurons sensitive to color, we drew the color field on the CIE color space where responses were obtained. The location and the extent of the color field in the color space differed from cell to cell, and collectively they covered almost the entire space tested.

Brief reports of these experiments have appeared elsewhere (Komatsu et al., 1989, 1990).

\section{Materials and Methods}

Behavioral task. Two macaque monkeys (Macaca fuscata) were used for the experiments. During the experiments, the monkeys sat in a primate chair and faced the screen of a color monitor, which subtended $20^{\circ}$ in visual angle horizontally and $13^{\circ}$ vertically. Each monkey was trained to perform a fixation task (Wurtz, 1969). A trial started when a small stationary spot (fixation spot) appeared on the screen. The monkey was required to foveate the fixation spot within $400 \mathrm{msec}$ after it 
appeared and to maintain its gaze within $1^{\circ}$ from the spot for the rest of the trial. During the fixation, another visual stimulus was presented, and it was this visual stimulus that we varied to study response selectivity. The fixation spot stayed on during the course of a trial except for the period around the stimulus presentation. This "blink" of the fixation spot was introduced to avoid any modulatory effect of the fixation spot on the response to the stimulus (Richmond et al., 1983). The blink period started $600 \mathrm{msec}$ after the monkey directed its gaze to the fixation spot, and lasted $1 \mathrm{sec}$. The stimulus was presented for $400 \mathrm{msec}$ in the middle of the blink. After the blink period, the fixation spot reappeared and dimmed after a random period $(0.4-1.6 \mathrm{sec})$. One monkey was required to detect the dimming by pressing a lever in addition to keeping its gaze on the fixation spot. Another monkey was required only to fixate. At the end of a successful trial, a drop of water was delivered to the mouth as a reward, the fixation spot was turned off, and an intertrial interval of $3 \mathrm{sec}$ started. Eye position was monitored using the magnetic search-coil technique (Robinson, 1963), or electrooculography in some of the early experiments. If the monkey's eye deviated from the fixation point more than $1^{\circ}$ at any time during the trial, the trial was automatically terminated without reward and the intertrial interval started.

Procedure of surgery and recording. A stainless steel recording chamber and a socket for connecting the monkey's head to the primate chair were fixed to the skull using standard sterile surgical techniques and sodium pentobarbital anesthesia. A search coil was also surgically placed under the conjunctiva of one eye using the method of Judge et al. (1980) and was connected to a plug on top of the skull. The recording chamber, the socket, and the eye coil plug were all embedded in acrylic that covered the top of the skull and connccted to the skull by implanted bolts.

The recording chamber was above the dorsal surface of the cortex, and electrodes were advanced vertically using a hydraulic microdrive (Narishige). In each hemisphere, recordings were done in two stages. In the first stage, we performed a general survey of the neural properties in the inferior temporal (IT) cortex including the lower bank of the superior temporal sulcus (STS). A glass-coated tungsten microelectrode was advanced through the dura in a different location each day. In the second stage, thin-wire tungsten microelectrodes coated by parylene (Micro prove) were advanced into the brain through a stainless steel guide tube. The tip of the guide tube was positioned $3-5 \mathrm{~mm}$ above the target site in IT cortex. This allowed concentrated sampling of single units from an area of interest. At the end of the recording from a guide tube, an electrolytic lesion $(9 \mu \mathrm{A}$ for $60 \mathrm{sec})$ was made for later identification of the recorded sites.

Neural signals were amplified and discriminated on the basis of spike amplitude and converted to pulses. The unit pulses and behavioral events were recorded by a computer with a time resolution of $1 \mathrm{msec}$ and displayed on line. Eye position was also continually displayed.

At the end of the experiments, monkeys were deeply anesthetized with sodium pentobarbital and perfused through the heart with saline followed by either $10 \%$ formalin or $0.8 \%$ paraformaldehyde plus $1 \%$ glutaraldehyde fixative. The brain was then removed from the skull, sectioned in the frontal plane, and stained with cresyl violet. The sites of electrode penetrations, guide tubes, and microlesions were identified on the histological sections under microscopic examination.

Color stimulus. Color stimuli were generated by a frame buffer (TEGO CGC4K) in an NEC PC9801 computer and displayed on a color monitor (NEC PC-KD854 or Mitsubishi XC3715C). Chromaticity coordinates of the three primaries of the monitors are indicated in Figure 1. The triangular region delimited by three primaries defines the "color space" that could be tested with each monitor. We studied the color selectivity of an IT neuron by comparing the magnitudes of the responses to colors at different locations in this space. Throughout this article, we will use the CIE (Commission Internationale de l'Eclairage) 1931 standard colorimetric system to represent colors used in the experiments.

To generate a color, we specified a set of three numbers $(r, g, b)$ on the computer, which determined each component of the analog RGB output of the frame buffer to the monitor. Each of these three numbers had a precision of four bits. Thus, $16^{3}(4096)$ stimuli differing color, luminance, or both could be generated. We measured the chromaticity coordinates and the luminance of all 4096 stimuli and selected a subset of colors that were distributed in the color space as evenly as possible. Several such sets of colors were used for different purposes. The number of colors in each set ranged from 9 to 50 . Each color in a set had a luminance that was within $0.1 \log$ unit of a base luminance, which might

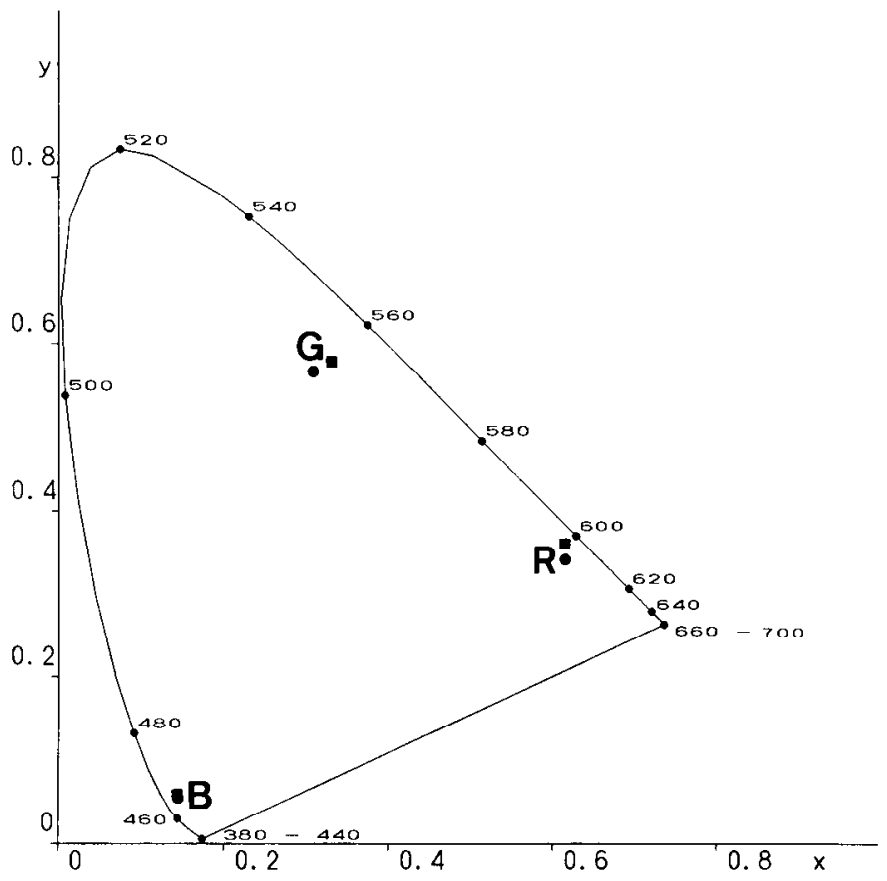

Figure 1. CIE 1931 chromaticity diagram and the spectrum locus. Chromaticity coordinates of the three primaries of two color monitors used in the experiments are indicated by solid circles and squares marked $R, G$, and $B$.

be $4 \mathrm{~cd} / \mathrm{m}^{2}, 8 \mathrm{~cd} / \mathrm{m}^{2}$, or $16 \mathrm{~cd} / \mathrm{m}^{2}$. The effects of luminance were tested by comparing the color selectivity obtained at these three different luminance levels. To map the responses of a cell in the color space, we first used smaller sets of colors that consisted of 13 colors (or 9 in some of the earlier experiments). Then, to determine the distribution of the responses in the color space in more detail, a subset of cells was tested by using larger sets of colors that consisted of 30 to 50 colors. The chromaticity coordinates and the luminance of the stimuli were measured by using a colorimeter (Minolta CS100) that gives $x, y$, and $Y$ values of the CIE colorimetric system. The accuracy of the colorimeter was tested by measuring the chromaticity coordinates of standard illuminant $\mathrm{A}$ generated using a calibrated tungsten bulb and monochromatic lights of three different wavelengths $(470,560$, and $610 \mathrm{~nm} ; 5$ $\mathrm{nm}$ half-bandwidth) generated by a monochrometer (Shimadzu). Errors in $x$ and $y$ values for the standard illuminant $\mathrm{A}$ were 0.007 for each value, and less than 0.017 for any of the monochromatic lights measured. Color of the stimuli used for the experiments was measured at the beginning and the end of a session of the experiments, and each measurement gave almost identical values.

To study the color selectivity of a neuron, stimulus color was varied while keeping its size, shapc, and the rctinal location fixcd. For one monkey, the color stimulus was always a square. For the other, one of several geometrical shapes was used. For this animal, we identified the best combination of color and shape qualitatively by presenting stimuli with various combinations of these parameters, and used the shape judged as the best for quantitative measurements of color selectivity. The size of the stimulus was selected to maximize neuronal responses in both animals. In each trial, a stimulus of homogeneous color was presented on a dark, uniform gray background $\left(0.1\right.$ or $\left.1.3 \mathrm{~cd} / \mathrm{m}^{2}\right)$ on the color monitor. The color of the stimulus for each trial was randomly chosen from one of the predetermined sets of colors. This was repeated until each color was presented four (or sometimes six) times. The stimulus was always centered on the fovea in these tests. The extent of the receptive field was measured by presenting the preferred stimulus at various positions on the display. For each neuron, discharge rates during stimulus presentation to a set of colors were statistically evaluated by analysis of variance (ANOVA), followed by Fisher's least significant difference test that compared the discharge rates to each color and that to the optimal color. Significance of the response to each color was 
Figure 2. Location of recording sites. $A$, Lateroventral view of the brain of one of the monkeys used for the experiments. The parallel lines indicate the approximate anterior and posterior extent of the recording sites. In this hemisphere, a site where color-selective cells were recorded was injected with a small amount of HRP at the end of the experiments using a microsyringe. The small circular patch at the arrow is a slight injury caused by this procedure and marks the site of injection. The site is at the convexity of IT cortex slightly lateral to the anterior middle temporal sulcus. $B$, Frontal section of the IT cortex and the surrounding cortex at a stereotaxic coordinate of about anterior 19 $\mathrm{mm}$. The shaded area indicates the recording sites at this anterior level. $\mathrm{Re}$ cording sites include both the IT gyrus and the ventral bank of the STS, but the lateralmost part of the IT cortex was not sampled. The solid circle near the anterior middle temporal sulcus indicates the site of the electrolytic lesion shown in $C$. This section is taken from the other cerebral hemisphere of the same monkey as that shown in $A$. $C$, Enlarged view of the recording sites and an electrolytic lesion indicated by an arrow in the IT gyrus. This lesion was made at the end of the experiments using one of the guide tubes from which a large number of color-selective cells were recorded. The same section as depicted in $B$ is stained by cresyl violet. $A M T S$, anterior middle temporal sulcus; $L F$, lateral fissura. Scale bar, $1 \mathrm{~mm}$.
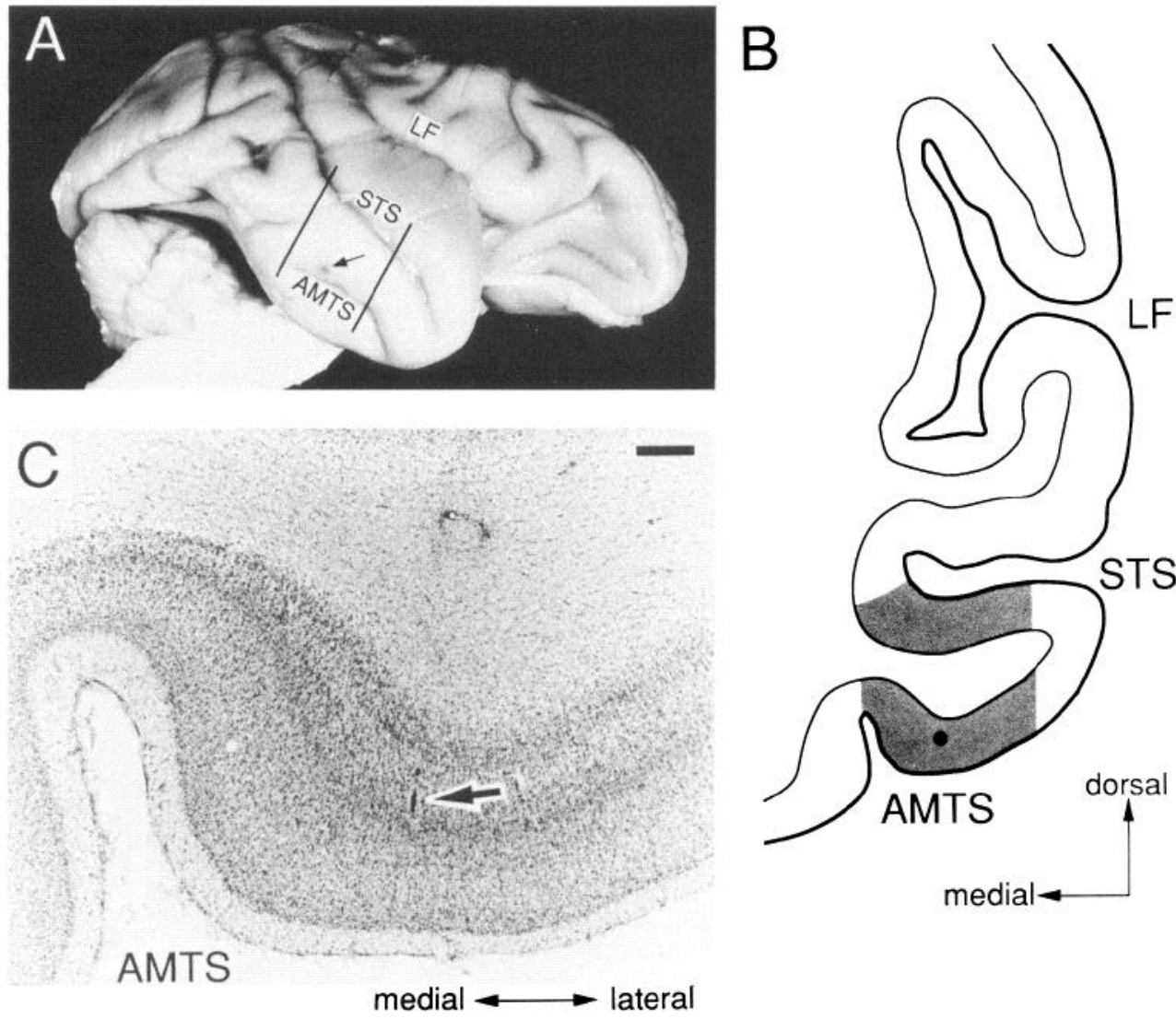

media lateral evaluated by Student's $t$ test by comparing the discharge rate before and during the presentation of a given color.

During the general survey of the neural properties of IT cortex, we used various kinds of visual stimuli in addition to the colored geometrical stimuli. These include pictures of natural objects or scenes, various textured patterns, and so on. These images were stored in a video disk and presented on a TV monitor during a trial.

\section{Results}

The anterior part of the IT cortex including the ventral bank of the STS was mapped in four hemispheres of two awake behaving monkeys. We recorded 492 single and multiple neurons during the general survey of the neuronal properties in this area. Of these, 151 neurons were activated by the simple colored geometrical stimuli strongly enough to allow further test of the properties of the cells using simple stimuli. Consistent with the previous studies (Gross et al., 1972; Desimone and Gross, 1979), these neurons had large receptive fields that always included the fovea and usually covered the entire monitor screen. We tested the color selectivity of these 151 neurons, and 99 neurons selectively responded to different colors. Color-selective neurons were distributed throughout the region we recorded, but there was variation in the prevalence of such cells. In the two hemispheres of one monkey, color-selective neurons were most frequently observed in a region slightly lateral to the anterior middle temporal sulcus. Among the cells that did not respond clearly to simple geometrical stimuli, 238 cells were tested with more complex stimuli. About half(121) responded to pictures of nat- ural objects such as human faces, natural scenes, or random dot patterns. The color selectivity of these cells was not tested.

Eight stainless steel guide tubes, two for each hemisphere, were introduced into the areas where we found color-selective cells during the general survey to allow concentrated recording from these areas. One hundred and seventy-three single neurons were recorded from these guide tubes, and of these, $155(90 \%)$ responded to simple colored geometrical stimuli. Subsequent analysis is based on these cells.

Figure 2 illustrates the area of anterior IT cortex we surveyed. The anterior and the posterior extent of the recorded area is shown by a pair of parallel lines in Figure $2 A$. As is shown in Figure $2 B$, the recorded sites in the coronal section included the ventral bank of the STS and the ventral part of the gyrus of IT cortex. The lateral part of the gyrus was not surveyed. A mark left by an injection of HRP at the site accessed by one of the guide tubes can be seen in Figure $2 A$, and an electrolytic lesion made at the end of a penetration through one of the guide tubes is shown at the arrow in Figure $2 C$.

\section{Color selectivity of IT neurons}

Of the 155 neurons that were sampled from the guide tubes and were activated by colored stimuli, 137 showed color selectivity. Responses from one color-selective IT neuron are shown in Figure 3. Histograms and rasters show its responses to 16 different color stimuli with the same size, shape, and retinal location. A clear increase of the discharge rate occurred at the 

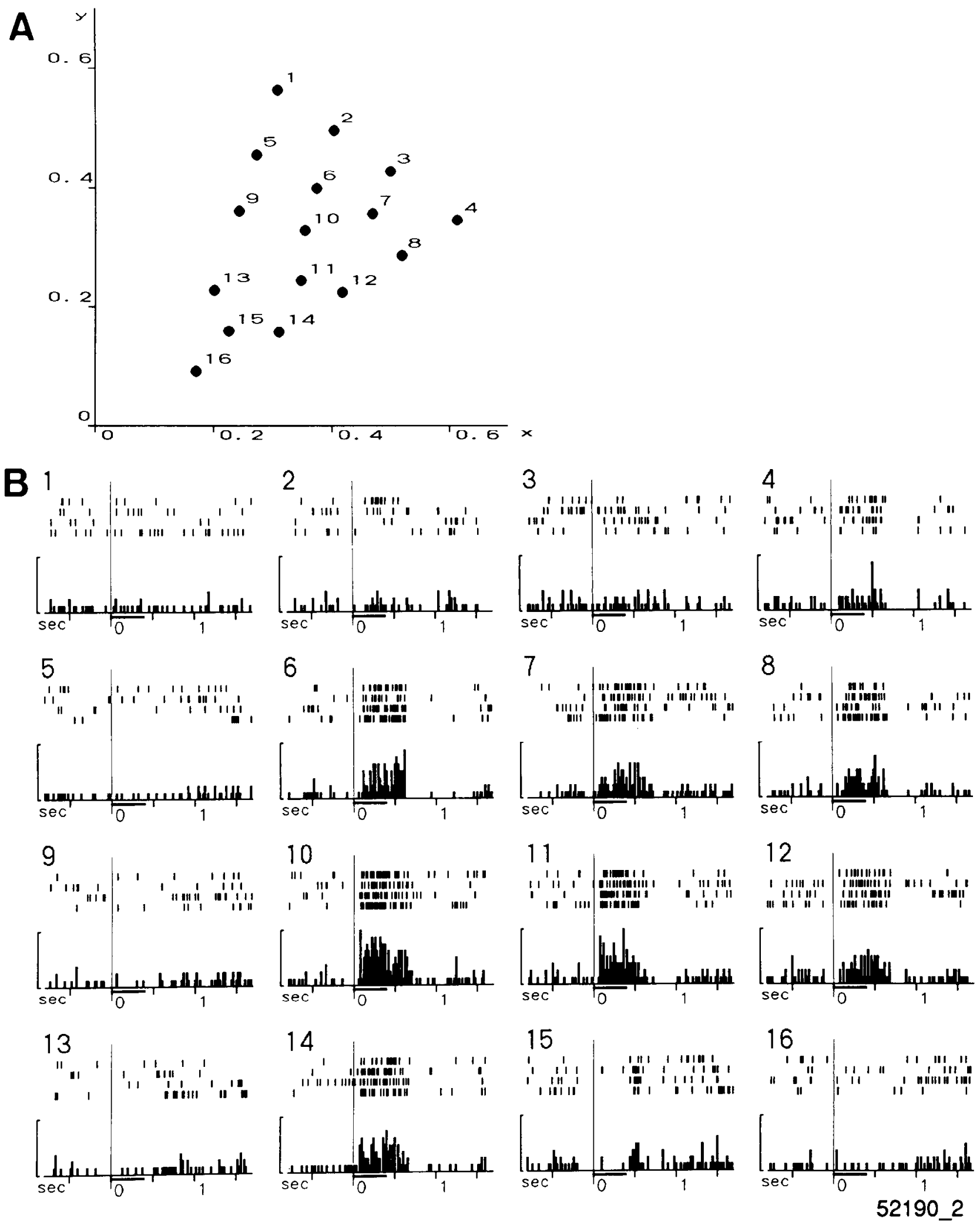

Figure 3. Discharges of a color-selcctive ccll to 16 different color stimuli. Chromaticity coordinates of the 16 color stimuli are shown in $A$ by solid circles. In $B$, histograms and rasters show the responses of the cell to these 16 color stimuli. Numbers at the left top corner of each raster correspond to those in $A$. Rasters and histograms are aligned at the onset of the stimulus. Each color stimulus was presented for a $400 \mathrm{msec}$ period that is indicated by the thick horizontal line below each histogram. The short vertical lines on the raster display indicate cell discharges; successive lines represent successive trials. The peristimulus histogram is the sum of a series of trials. The tick marks on the abscissa are 500 msec. In these histograms, bin width is $20 \mathrm{msec}$, and the calibration bar at the left of each histogram indicates $100 \mathrm{spikes} / \mathrm{sec}$. The shape and size of these 16 stimuli were the same (circle, $3^{\circ}$ in diameter). All stimuli were presented at the center of the visual field. The luminance of each stimulus was within $0.1 \log$ unit of $8 \mathrm{~cd} / \mathrm{m}^{2}$. The luminance of the background was $1.3 \mathrm{~cd} / \mathrm{m}^{2}$. The number at the right bottom corner is the cell's name. 
Figure 4. Discharges of the same cell as shown in Figure 3 to 48 different color stimuli with the same parameters as described in the Figure 3 caption. To show how response varied across the color space, the response to each color is represented as a diameter of a circle and plotted at the position that corresponds to the chromaticity coordinates of that color. The diameter of each colored circle indicates the average discharge rate of the entire period of the stimulus presentation after allowing 100 msec for the latency of the visual response. To visualize the preferred hue of the cell, each circle is painted with the same color as used for the stimulus. The diameter of each open white circle indicates the average discharge rate of the $300 \mathrm{msec}$ period preceding the presentation of each color stimulus in which neither the fixation spot nor the color stimulus is presented. The scale is 60 spikes/sec.

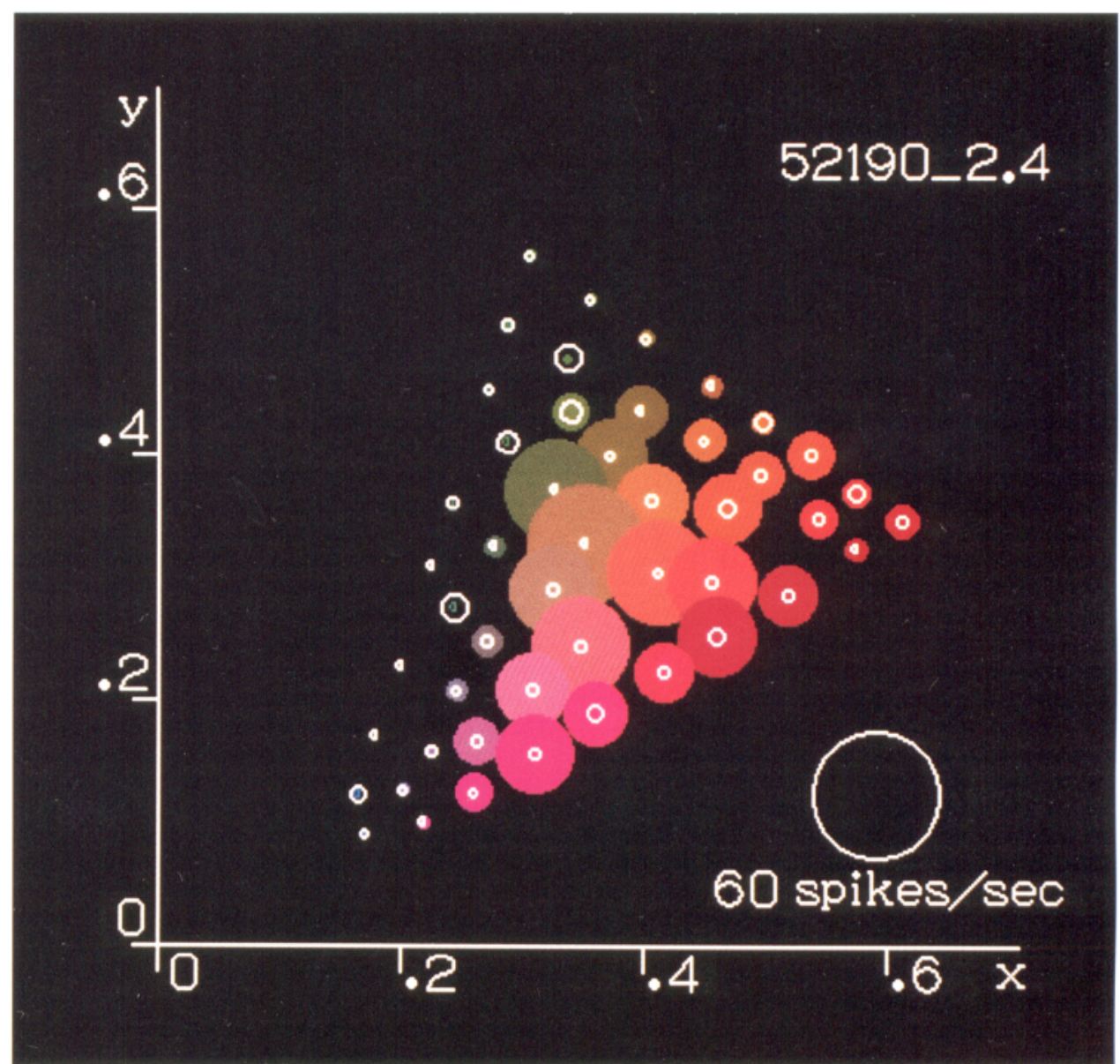

onset of some of the stimuli with a latency of about $100 \mathrm{msec}$, and this increased rate of discharge was largely maintained during the entire period of the stimulus presentation. For some of the stimuli, such as stimulus 15 , there was a weak transient activation at the offset of the stimulus. Off-responses were unusual among the cells we recorded and were usually weaker than on-responses. We will describe only the on-responses of these cells.

The cell shown in Figure 3 responded maximally to stimulus 10 and somewhat less strongly to stimuli $6,7,8,11,12$, and 14. Figure $3 A$ shows the chromaticity coordinates of these 16 colors. The stimuli that activated this cell were not randomly distributed in the color space, but were instead confined to a continuous region. Figure 4 shows more clearly how the magnitudes of the responses of this neuron were distributed in the color space. Responses to 48 different luminance-matched colors (including those shown in Fig. 3) are represented by the diameters of circles and plotted in positions that correspond to their chromaticity coordinatcs. A colored circle represents discharge rate during stimulus presentation, and a white circle represents that before stimulus presentation. Strong responses occurred when the color of the stimulus was in a single continuous region in the color space. The maximal response was obtained by pink of low saturation, and weaker responses were obtained using purple and desaturated red, orange, and yellow stimuli. Blue and cyans produced no response.
Figure 5. Discharges of the same cell as shown in Figure 4 to 13 color stimuli darker than those used before. The luminance of the stimuli was within $0.1 \log$ unit of $4 \mathrm{~cd} / \mathrm{m}^{2}$. Other parameters were unchanged. 

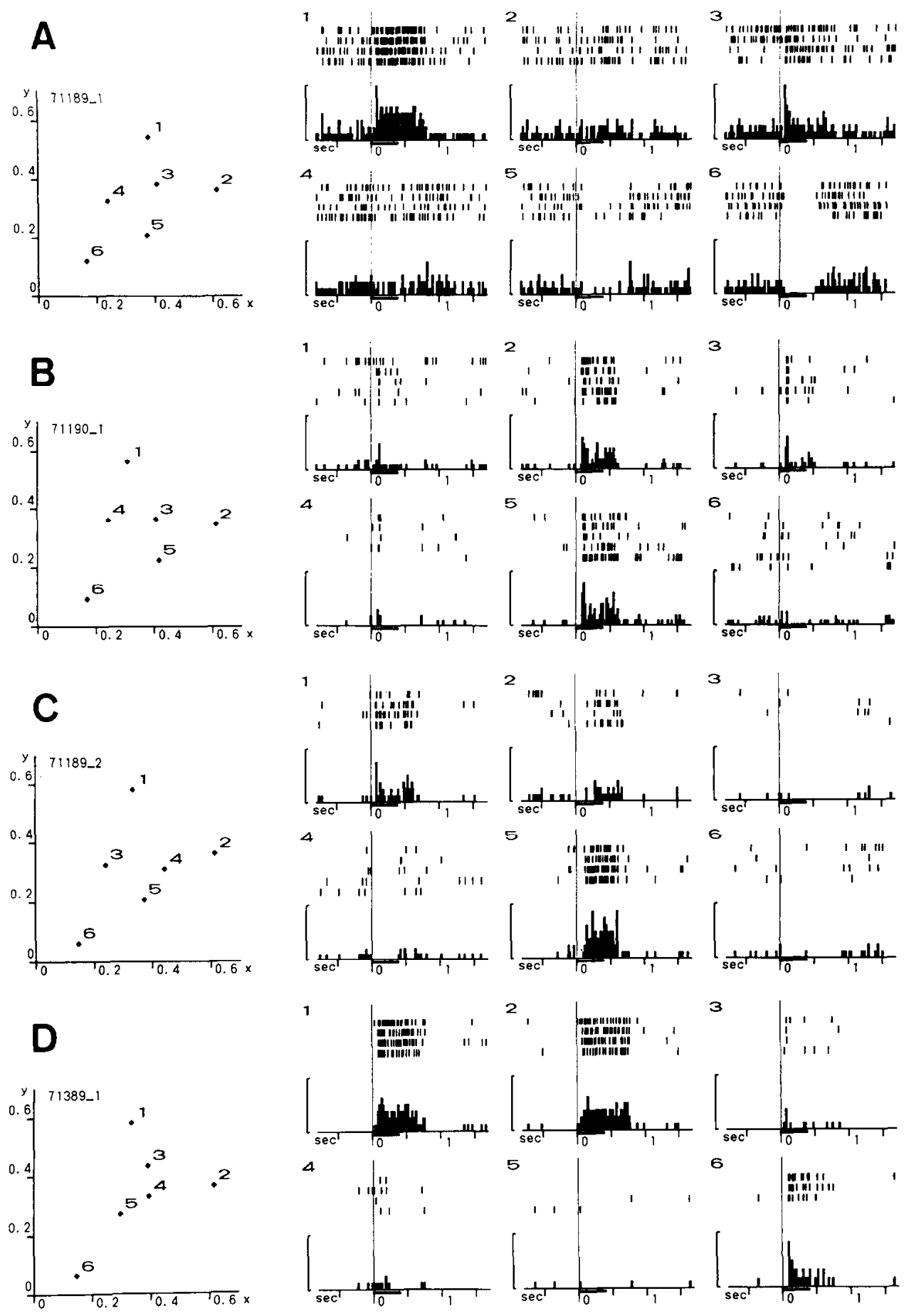
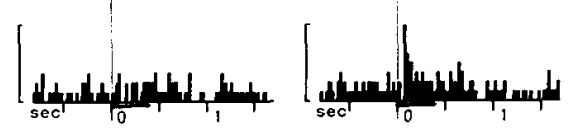

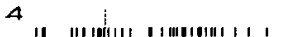

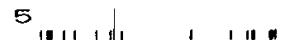

6
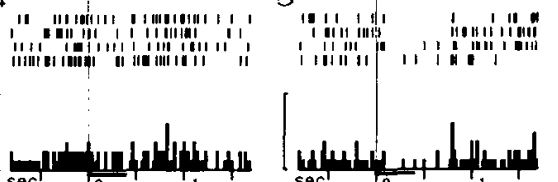

, inini...

;

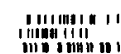
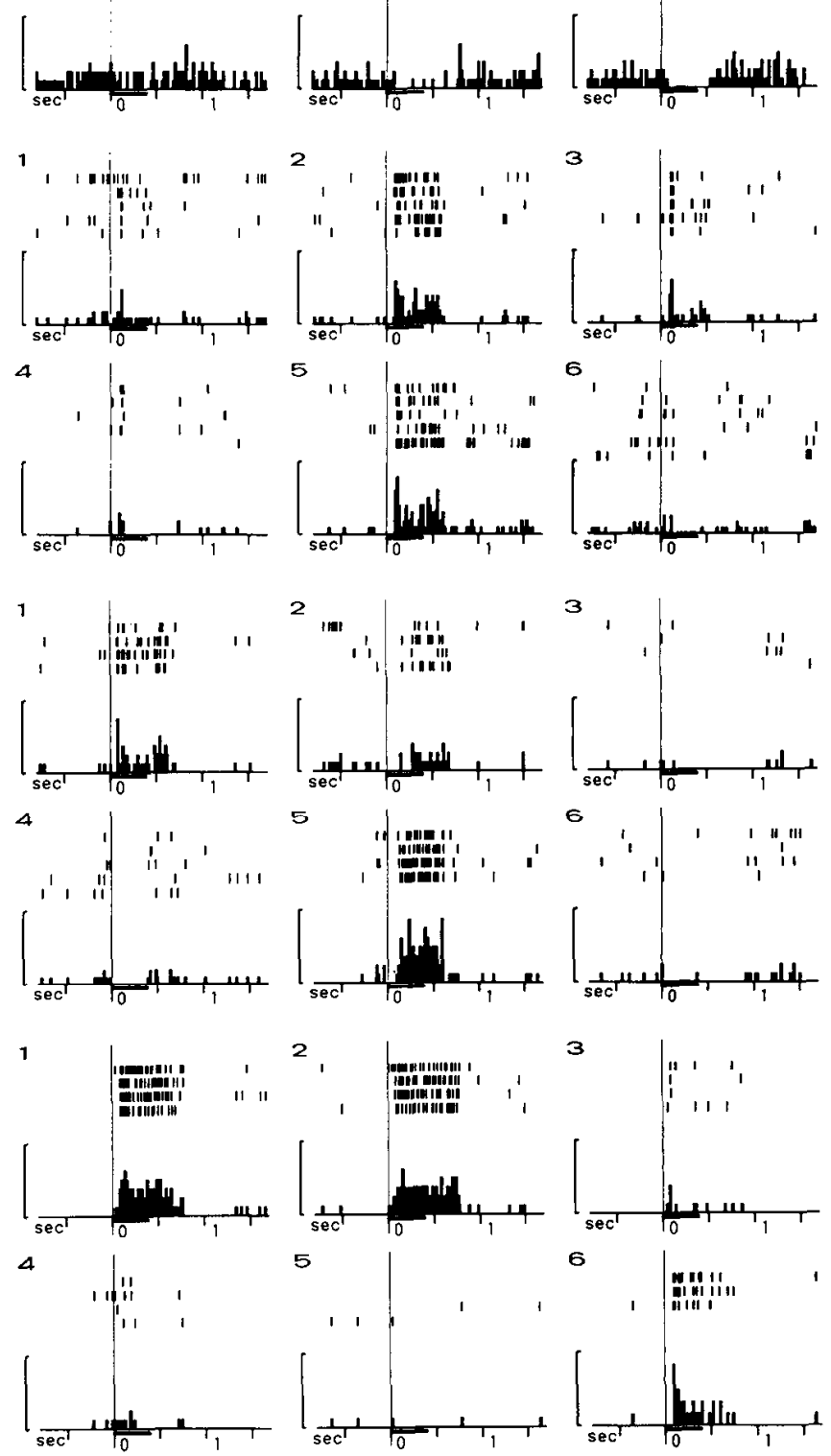

Figure 6. Discharges of four color-selective cells to six different color stimuli are shown by rasters and histograms. $A-D$ represent different cells. For each cell, chromaticity coordinates of these six colors are shown on the chromaticity diagram at the left. Numbers on the chromaticity diagram correspond to those on rasters. Other conventions for rasters and histograms are as in Figure 3 . The luminance of the stimuli was the same as that described for Figure 3. The luminance of the background was 0.1 $\mathrm{cd} / \mathrm{m}^{2}$ for $A, C$, and $D$ and $1.3 \mathrm{~cd} / \mathrm{m}^{2}$ for $B$. The stimulus was square in $A, C$, and $D$ and a square-wave grating (3.3 cycles/degree) composed of the test color and the background color in $B$. The size at the edge is $0.11^{\circ}$ in $A, 1.0^{\circ}$ in $B$, $0.27^{\circ}$ in $C$, and $2.2^{\circ}$ in $D$.
Although these results suggest a clear color selectivity of this neuron, we must consider another possible source of the differences in the responses to the color stimuli. Although the shape, size, and retinal location were the same for all the stimuli, the luminance varied within a small range around $8 \mathrm{~cd} / \mathrm{m}^{2}$. If luminance varied systematically with color, the differences in the magnitude of the responses might depend on luminance rather than color. The data in Figure 5 show the responses of the same cell to darker stimuli. The responses to 13 color stimuli whose luminance was within $0.1 \log$ unit of $4 \mathrm{~cd} / \mathrm{m}^{2}$ are shown in the same format as Figure 4. The distribution of the response mag- nitudes in the color space was very similar to that obtained with the brighter stimuli. This indicates that a small variation in the luminance within the set of stimuli used in the test of Figure 4 cannot explain the big difference in the responses to the different colors.

Figure 6 shows four other examples of responses from colorselective cells. For each cell, responses to six different colors are shown in rasters and histograms. The responses of these cells are plotted on the chromaticity diagram in Figure 7. Figures $6 \mathrm{~A}$ and $7 A$ show responses from the same cell. As is seen in Figure $6 A$, this cell showed a strong excitatory response to color 1 and 


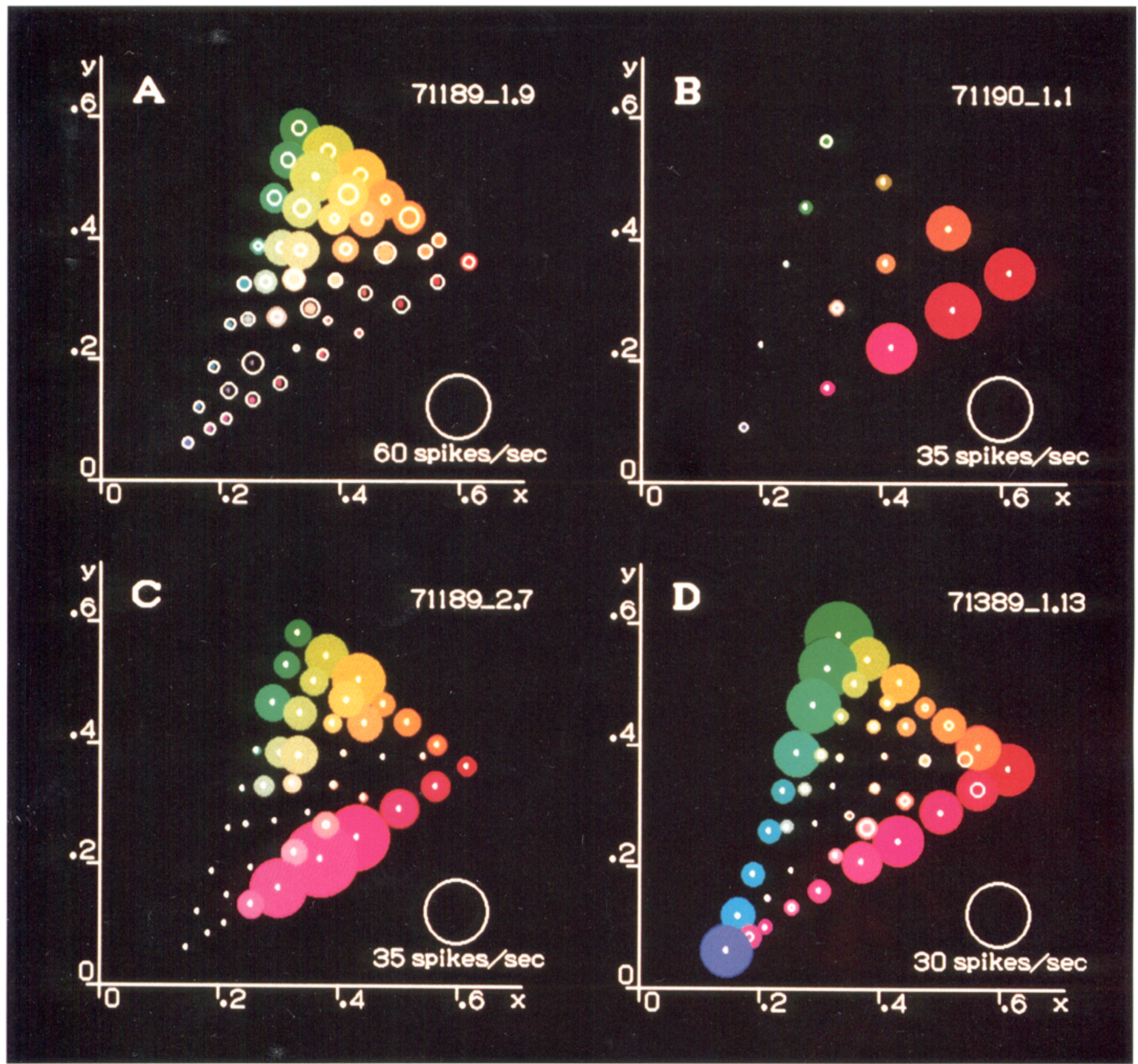

Figure 7. Discharges of the same cells as shown in Figure 6 are plotted on the chromaticity diagram in the same way as in Figure 4. $A-D$ in this figure and in Figure 6 represent the same cells. In $A, C$, and $D$, discharges to 44 different colors are plotted. In $B$, responses to 13 different colors are plotted. The luminance of the stimuli and the background and the shape and size of the stimuli are as described for Figure 6.

a weak response to color 3 . This cell had a clear background discharge, and this made it possible to see inhibitory responses to colors 5 and 6 . Colors 2 and 4, which lay between the colors generating excitatory responses and those generating inhibitory responses, produced no clear response. This suggests an ordered distribution of the response magnitude in the color space. Figure $7 A$ shows this to be the case. The maximum response was obtained by yellow-green, and as the distance from this color increased in the color space, the magnitude of the neural response gradually decreased and finally inhibitory responses took over. Although the preferred color differed between the cells shown in Figures 4 and $7 A$, both had a single peak of response mag- nitude in the color space, together with a surrounding field in which weaker responses could be obtained. We call such a responsive region in the color space a color field in an analogy with the receptive field, which is defined as a responsive region in the visual field. The cells shown in Figures 4 and $7 A$ had a color field that had a single peak. The data shown in Figures $6 B$ and $7 B$ are from another such a cell. This cell was activated only by reddish colors.

The cells whose responses are shown in Figures 6 and 7, $C$ and $D$, had a different type of color selectivity. In Figure $6 C$, responses occurred to colors 1,2 , and 5 , but there was no response to the colors between, such as colors 3 and 4 . As is seen 
in Figure $7 C$, there were two peaks of response magnitude in the color space, one near yellow and the other near purple. This cell's color field had two separate responsive regions rather than a single continuous region. This cell was recorded from the same penetration as the cell shown in Figures $6 A$ and $7 A$, at a depth about $400 \mu \mathrm{m}$ more ventral. The responsive region in Figure $7 C$ including yellow and green had an extent similar to the excitatory region in Figure $7 A$. In Figure $6 D$, strong responses were observed to colors 1,2 , and 6 . These colors approximately correspond to three primary colors of our display. There was no response or only very weak response to colors 3,4 , and 5 that were situated in the central region of the color space. As can be seen in Figure $7 D$, this cell was activated by colors along the edge of the color triangle defined by the three primary colors, but the response became weaker to colors within the triangle and no response was observed at the center of the triangle. This distribution of responses suggests that the cell was sensitive to the saturation of the stimulus. It also had some hue preference. Hues close to the primary colors were preferred, and there were three separate peaks in the color field of this cell.

\section{Quantitative analysis of the color selectivity}

To analyze the color selectivity quantitatively, we have chosen a standard set of test colors ( 13 colors in most of the experiments or 9 in some of the earlier experiments) that cover the color space as evenly as possible. We then calculated color index as a measure of how a cell discriminated the preferred color from the nonpreferred color. We defined color index as 1 - (minimal response)/(maximal response), where response is (average discharge rate during stimulus presentation) - (that before presentation). We also evaluated statistically whether the variation of the responses among the set of test colors is significant by ANOVA. Of the 155 neurons that were sampled from the guide tubes, sufficient data were obtained using a standard set of test colors in 65 neurons ( 55 using 13 colors, 10 using 9 colors), and quantitative analysis of the color selectivity was performed for these 65 neurons. Figure 8 shows how the color index was distributed among these cells. All 65 cells had a color index greater than 0.25 , and the percentage of cells that had a color index larger than a criterion value gradually decreased as the criterion value increased. About $50 \%$ of the cells ( 30 out of 65 ) had a color index greater than 1.0. Figure $8 B$ shows incidence of cells in which differences in the responses to various colors were statistically significant (light area, $p<0.05$, ANOVA) or not significant (dark area, $p \geqq 0.05$ ). The ratio between the statistically significant cells and those not significant sharply decreased for cells with color index less than 0.5 . Although there is no obvious division with regard to the distribution of color index in our sample of cells, sharp decline of the incidence of statistically significant responses for cells with a color index less than 0.5 leads us to divide our sample of cells at this level. We classified a cell to be color selective if it had a color index greater than 0.5 and if it showed statistically significant variation among the standard set of colors. If we use this criterion for the color selectivity of these cells, 46 cells ( 46 out of $65,71 \%$ ) are classified as color selective.

For the 65 cells tested by a standard set of colors, we defined the color field in a standardized fashion so that we could compare the location and the extent of the color fields of different cells in a precise way. Figure 9 shows how we defined the extent of the color field for two cells. In Figure 9, the chromaticity coordinates of the standard set of 13 colors used for one monkey
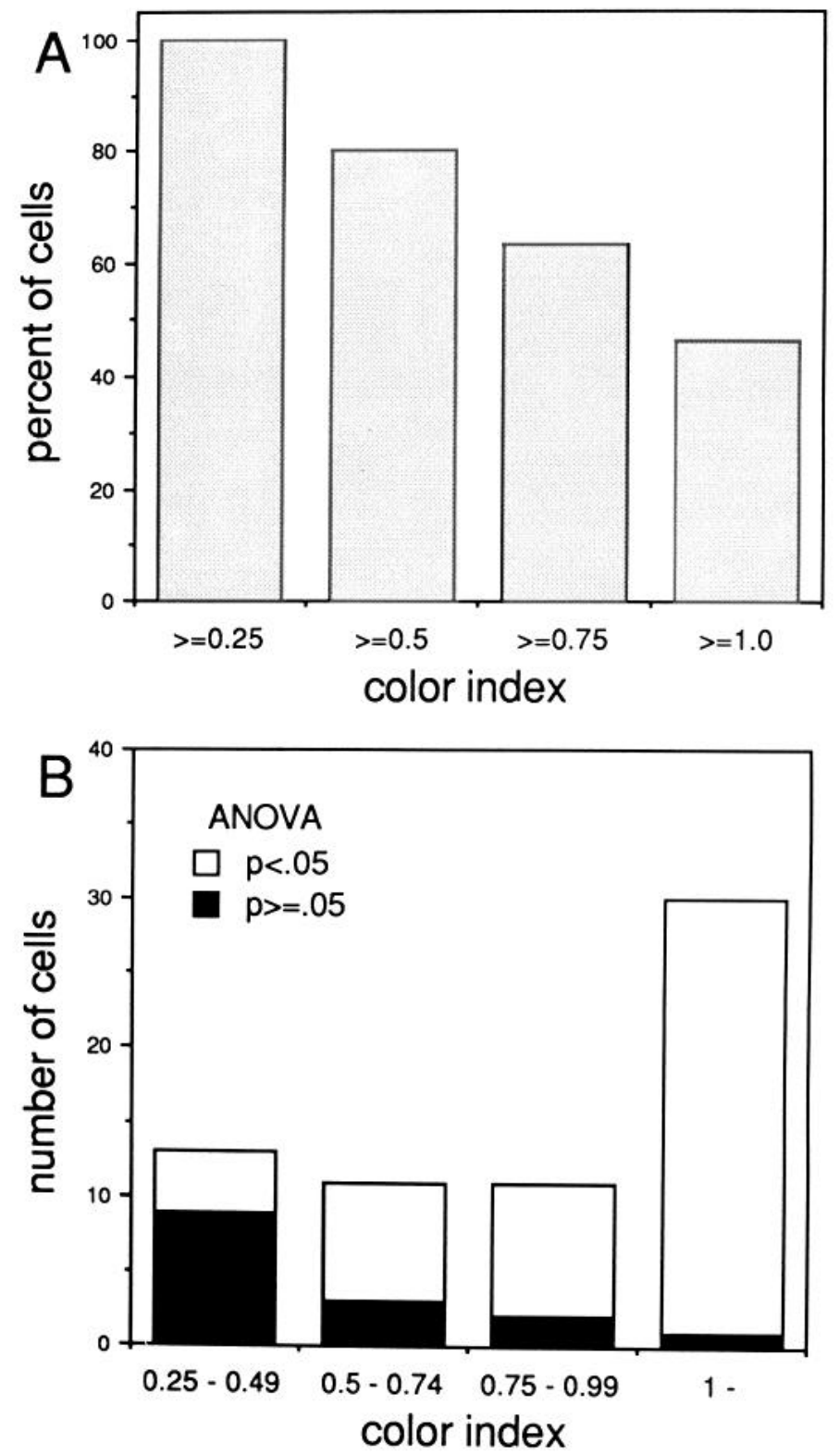

Figure 8. Distribution of the color index for 65 cells whose color selectivity was quantitatively analyzed. $A$, Percentage of cells with color indices greater than the values indicated on the abscissa. $B$, Number of cells with the color indices within the ranges indicated on the abscissa. The dark areas represent the cells in which variations of the responses to test colors were not statistically significant ( $p \geqq 0.05$, ANOVA); the light areas represent those statistically significant $(p<0.05)$.

are represented by the nodal points of the mesh. To determine the color field, the peak among the 13 responses was identified, and then linear interpolation was used to obtain the points on the line segments connecting neighboring pairs of nodal points where response magnitude would be $75 \%, 50 \%$, or $25 \%$ of the peak response. Points obtained in this way were connected to determine the extent of the region in the color space where responses would be larger than $75 \%$ (75\% color field), $50 \%(50 \%$ color field), or $25 \%$ ( $25 \%$ color field) of the peak. In Figure 9, an increase or a decrease in the discharge rate caused by a stimulus presentation is shown as a number beside each nodal point. The peak response in Figure $9 A$ was 29 spikes/sec, and 

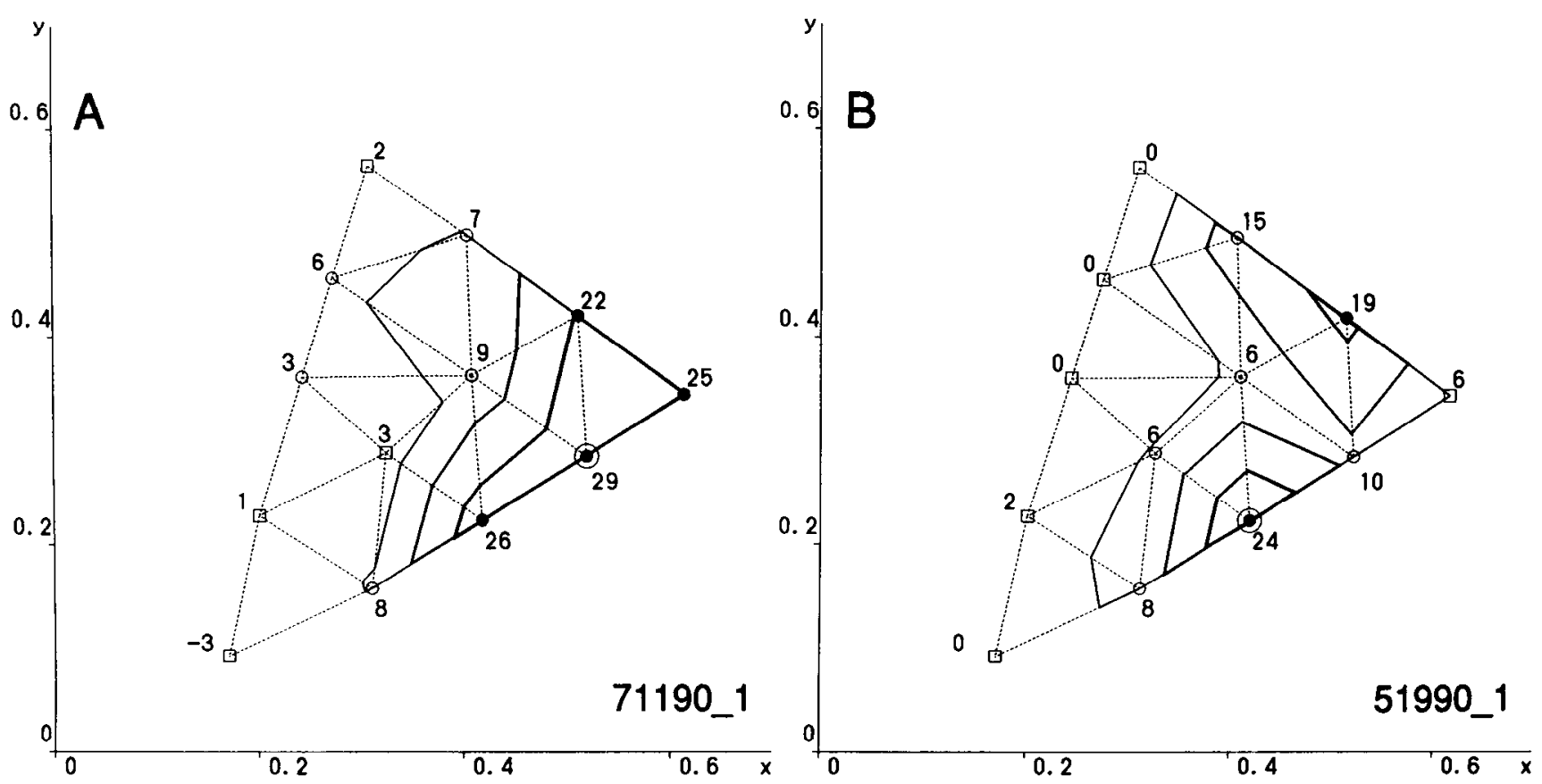

Figure 9. Determination of the extent of the color field of two cells. $A$ and $B$ represent different cells. The cell in $A$ is the same cell as shown in Figures $6 B$ and $7 B$. Magnitudes of the responses [(average discharge rate during stimulus presentation) - (that before stimulus presentation)] to 13 standard test color stimuli are indicated by numbers at the nodal points of the mesh. Each nodal point indicates the chromaticity coordinates of one of the stimuli. Linear interpolation was done to obtain points on the line segments connecting neighboring pairs of nodal points where response magnitude was $75 \%, 50 \%$, and $25 \%$ of the peak responses ( 29 spikes/sec in $A$ and 24 spikes/sec in $B$ ) indicated by large circles. Points obtained in this way were connected to determine the extent of the region in the color space where response was larger than $75 \%$ (thickest lines), $50 \%$ (medium lines), and $25 \%$ (thinnest lines) of the peak response, which we call $75 \%$ color field, $50 \%$ color field, and $25 \%$ color field, respectively. Solid circles, responses significantly different from the background discharge but not significantly different from the peak response; open circles, responses significantly different from both the peak and the background discharge; open squares, responses not significantly different from the background discharge.

in $B$ this was 24 spikes/sec. The $75 \%$ color fields, the $50 \%$ color fields, and the $25 \%$ color fields are enclosed by thick lines, medium lines, and thin lines, respectively. The example in Figure $9 A$ depicts the same responses shown in Figure $7 B$. By comparing Figures $7 B$ and $9 A$, it can be seen that the extent of the excitatory responsive field judged by eye lies somewhere between the $25 \%$ color field and the $50 \%$ color field. This was true for most of the cells analyzed. In contrast, the $75 \%$ color field indicates the most responsive region in the color field. There was a clear tendency for cells with higher color indices to have smaller color fields.

The cells shown in Figure 9, $A$ and $B$, had a different organization of the color field. The $75 \%$ and $50 \%$ color fields of the cell in $A$ were single continuous regions, but those in $B$ consisted of two separate regions. This is borne out by statistical evaluation of the responses to each color as indicated by marks at each nodal point. Solid circles represent responses significantly different from the background discharge but not significantly different from the peak discharge. Open circles represent responses significantly different from both the pcak and the background discharge. Open squares represent responses not significantly different from the background discharge. The solid circles in $A$ are contiguous in the mesh. We can classify such a cell as having a single peak. In $B$, solid circles are separated by open circles and not linked together, and this cell is classified as having multiple peaks (two peaks in this case). The cell shown in Figure $7 D$ is another example of this type of neuron. When plotted this way, some cells had a single region with solid circles and regions with open circles that were separated by nodes with squares. The cell in Figure $7 C^{\prime}$ is an example. We classitied this type of cell as having a single peak with multiple responsive regions. When we analyzed the organization of 46 color-selective neurons, 36 had a single peak with a single responsive region, 5 had a singe peak with multiple responsive regions, and 5 had multiple peaks. Altogether, 10 of $46(21.7 \%)$ of the color-selective cells had more complex color field organization.

\section{Representation of the color space by the population of IT neurons}

The location and the extent of the color field differed from cell to cell. To understand how IT cortex represents color, it is important to know the distribution of color fields in the population of IT neurons. Figure 10 shows examples of color fields for nine color-selective cells each of which had a single peak and a single responsive region. Most of the cells preferred highly saturated colors and had color fields whose peaks were on or near the edge of our color space, but a small number of cells ( 5 of 46 of the color-sclcctive cclls, $11 \%$ ) preferred desaturated colors. Cells shown in Figure 10, $H$ and $I$, are examples of this type of neuron. These cells had color fields that were islands within the color triangle. All such islandlike color fields were located near desaturated purple or red (pinks). It is interesting to note that in Kelly's (1943) study of color naming, pink was the only color given a different name from the corresponding saturated color, and occupies an islandlike region in color space. 

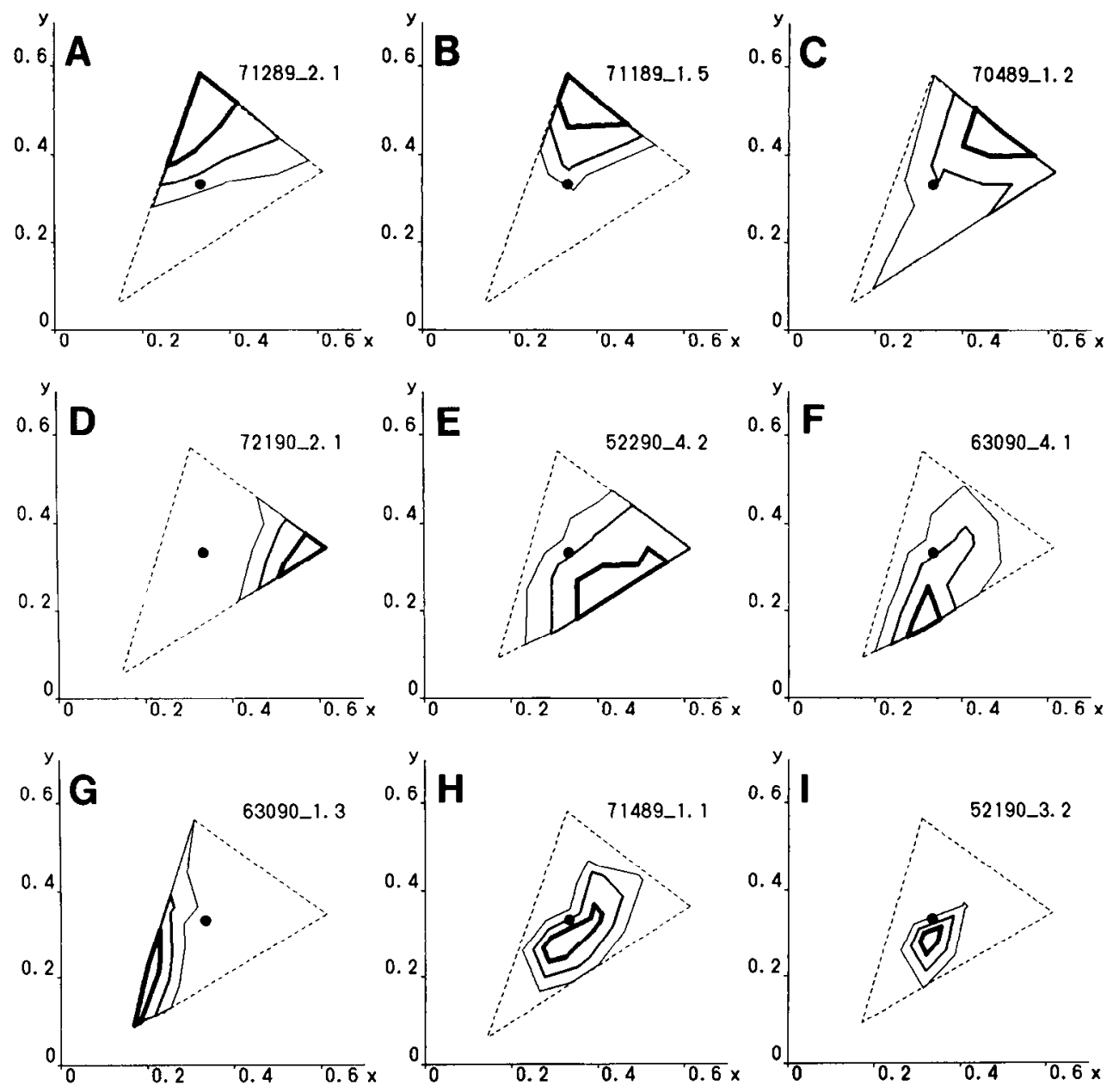

Figure 10. Examples of the $75 \%, 50 \%$, and $25 \%$ color fields of nine color-selective IT neurons. $A-H$ represent different cells. In each, the thickest line indicates the boundary of $75 \%$ color field, the medium line indicates that of $50 \%$ color field, and the thinnest line indicates the boundary of $25 \%$ color field. A broken line indicates the extent of the color space mapped. Solid circles indicate the white point defined as $x=$ 0.333 and $y=0.333$. In all records, the luminance of the stimulus was within $0.1 \mathrm{log}$ unit of $8 \mathrm{~cd} / \mathrm{m}^{2}$.

Although the color field of each cell shown in Figure 10 occupied only some part of the color space, the combination of the color fields of these cells covered most of our color space. Figure 11 shows superimposed plots of $50 \%$ color fields (top) and $75 \%$ color fields (bottom) of color-selective cells recorded from both monkeys. Only cells with color indices greater than 0.75 are plotted. For each monkey, the combination of $50 \%$ color fields covered the entire color space mapped in our experiments. The combination of $75 \%$ color fields also covered most of the color space, with a notable exception of a region adjoining the white point. It is unlikely that this sparing is an artifact of the limited sample sizes, because the population of color fields obtained from two monkeys showed sparing of the same region in color space. This spared region overlaps with the white/gray region of the color space and includes desaturated cyans. This indicates that none of the highly color-selective neurons (color index $>0.75$ ) in our sample were particularly sensitive to this region of the color space. In other words, the color fields of such cells were not centered at this region of the color space, and only the periphery of the color field included this region. On the other hand, less color-sensitive cells tended to have a larger color field that usually included this part of the color space. Therefore, though IT neurons as a whole represent entire color space, there seems to be a tendency for the more color-sensitive cells to be less sensitive to white/gray and desaturated cyans.

\section{Effects of the luminance of the stimulus}

Effects of stimulus luminance were tested by comparing the color fields obtained at different luminance levels. Color fields were plotted as described above. In addition to the $8 \mathrm{~cd} / \mathrm{m}^{2}$ luminance level (within $0.1 \log$ unit of $8 \mathrm{~cd} / \mathrm{m}^{2}$ ), two luminance levels each within $0.1 \mathrm{log}$ unit of $4 \mathrm{~cd} / \mathrm{m}^{2}$ or $16 \mathrm{~cd} / \mathrm{m}^{2}$ were employed. Luminance of the background was kept the same as that used in the previous experiments. The extents of the color spaces mapped at these three different luminance levels are shown in Figure $12 \mathrm{~A}$. The regions covered by stimuli at the 4 and $8 \mathrm{~cd} /$ $\mathrm{m}^{2}$ levels were almost identical, so that the boundary of the extent at the $4 \mathrm{~cd} / \mathrm{m}^{2}$ level is almost hidden. At the highest luminance, the tested region shrank away from colors such as red, purple, and blue, due to unavoidable properties of the color monitor. Figure $12 B$ shows three typical examples of the effects of the luminance of the stimuli on the color field and the peak response. Each of the three cells showed color selectivity at all luminance levels, and the color fields obtained at each luminance level had significant overlap. Shrinkage of the color field along the red-blue edge of the color triangle was observed at the highest luminance level in every cell, but this was due to the limitations of the region of color space tested. We tested the effect of luminance in 19 color-selective cells by comparing the color fields at more than one luminance level as described above. All cells showed an overlap of the $50 \%$ color field obtained at 


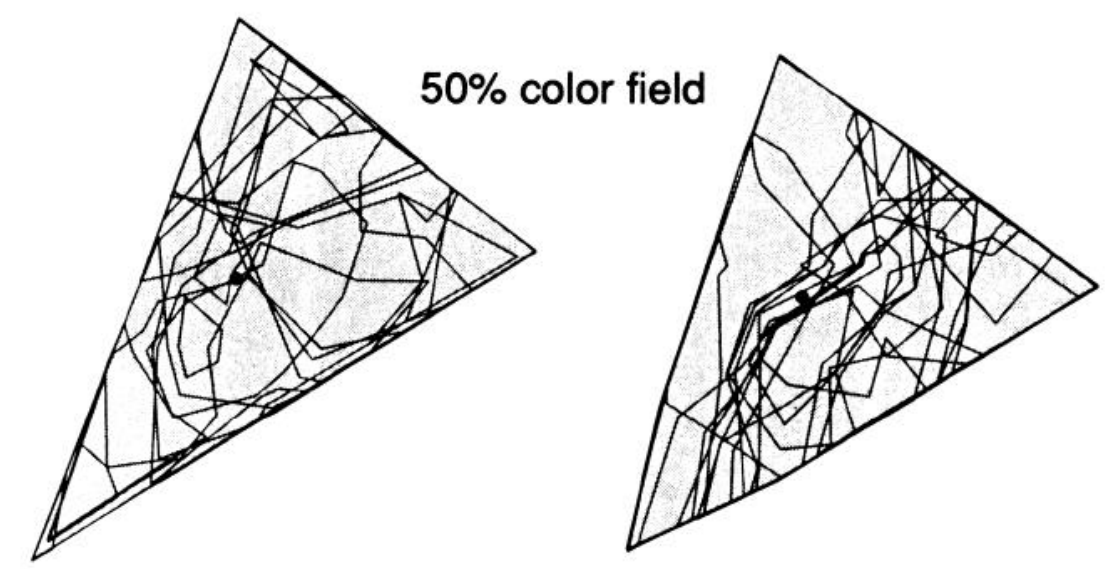

Figure 11. Superimposed plots of $50 \%$ color fields (top row) and $75 \%$ color fields (bottom row) obtained from two monkeys (left column and right column). Only data from cells that had color indices larger than 0.75 and that showed statistically significant responses $(p<$ 0.05 , ANOVA) are used for these drawings. Nineteen color fields for monkey BM05 and 19 color fields for monkey BM11 are superimposed. For each drawing, the shaded area indicates the region of the color space covered by the color field of at least one cell. Note that in either monkey, $50 \%$ color fields as a total covered the entire color space mapped in our experiments, whereas $75 \%$ color fields left a region adjoining the white point uncovered. The luminance of the stimuli used for the experiments was within $0.1 \log$ unit of 8 $\mathrm{cd} / \mathrm{m}^{2}$.
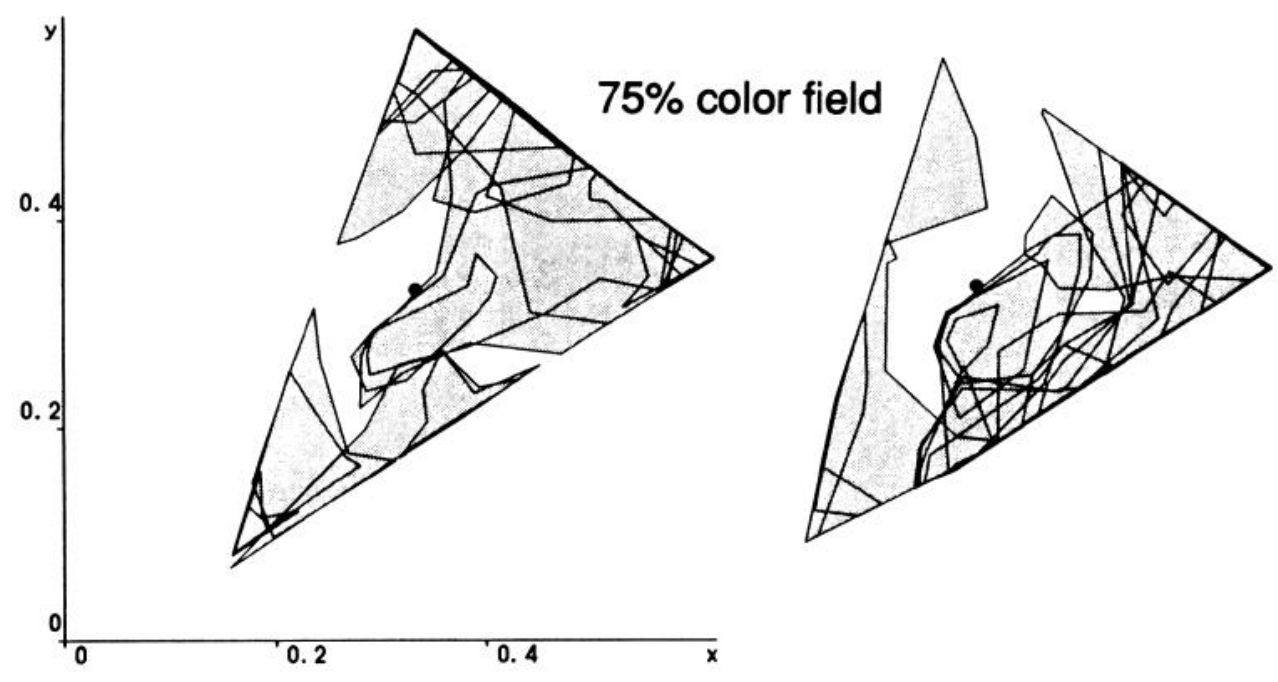

different luminance levels, as was the case for the cells shown in Figure $12 \mathrm{~B}$, and all cells but one showed an overlap of the $75 \%$ color field. In most cases the extents of the color fields were similar. This was true both for the $75 \%$ color field and $50 \%$ color field. In all cells, color index was greater than 0.5 at all luminance levels. These results indicate that the basic properties of the color selectivity of IT neurons are independent of the luminance, at least in the range tested. However, close inspection of data indicates that there are small but clear effects of the luminance on the neural responses. One effect is related to the extent of the color fields. For some cells, the size of the color field changed with the luminance of the stimulus, as can be seen in the left column in Figure $12 \mathrm{~B}$. For other cells, the position of the color field gradually shifted with stimulus luminance, as is seen for the other cells in Figure 12B. Another effect of the luminance observed in some cells was a change in the magnitude of the maximal response. We conclude that within the range of luminance we have tested, the color selectivity of IT neurons does not change significantly, but that we can also find several kinds of weak effects of luminance on either the extent of the color field or the response magnitude.

\section{Effects of the size of the stimulus}

Stimulus size often affected the responses of color-selective IT neurons. When we changed the stimulus size with other parameters kept constant, pronounced changes in the response magnitude were observed in many cells. Figure 13 shows different types of effects. Panel $A$ shows responses from cells that preferred larger stimuli over the range of sizes that we have tested. In $B$, the maximal response was obtained at some intermediate size. Cells in $C$ preferred smaller stimuli. In $D$, effects of the size were not clear. These data were collected using the preferred color of each cell. The color preference of a given neuron did not change with stimulus size. Figure 14 shows an example of a colorselective neuron that showed size preference. This is the same cell as shown in Figures $6 A$ and $7 A$. This cell showed excitatory responses to green or yellow-green (colors 1 and 2 in Fig. 14A), and inhibitory response to blue or purple (color 4 in $A$ ) when the stimulus was small. No response was obtained for red (color 3 in $A$ ). When the stimulus became larger, the responses became gradually weaker, but the preferred color was always green or yellow-green. Effects of size were examined for 31 cells. Of these, 
A

\section{extent of the color space mapped}

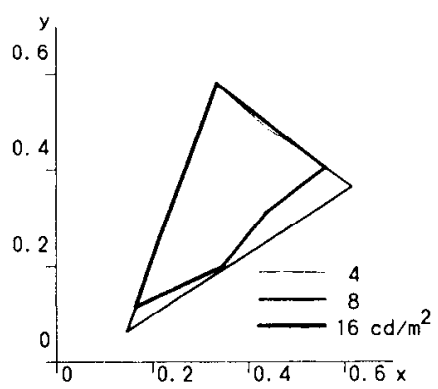

cell $70189-5$

$\operatorname{cell} 71389-2$

cell 71489

\section{$50 \%$ color field}
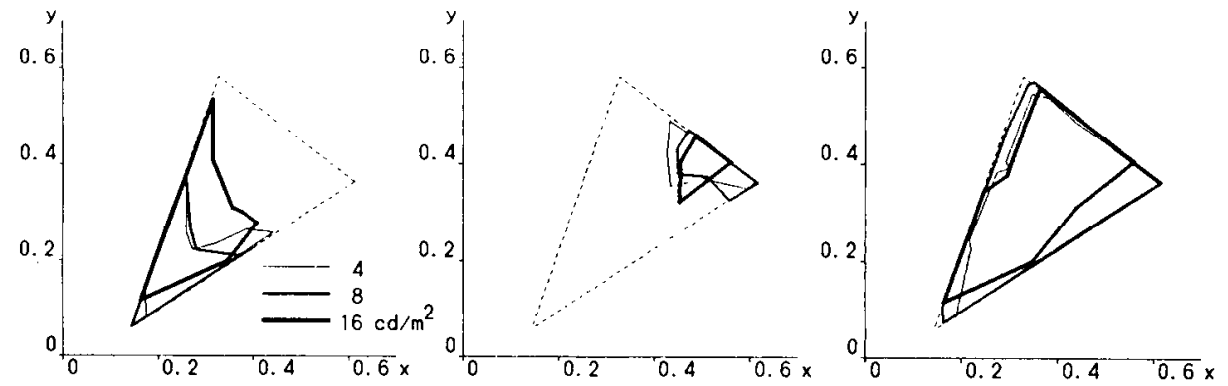

$75 \%$ color field
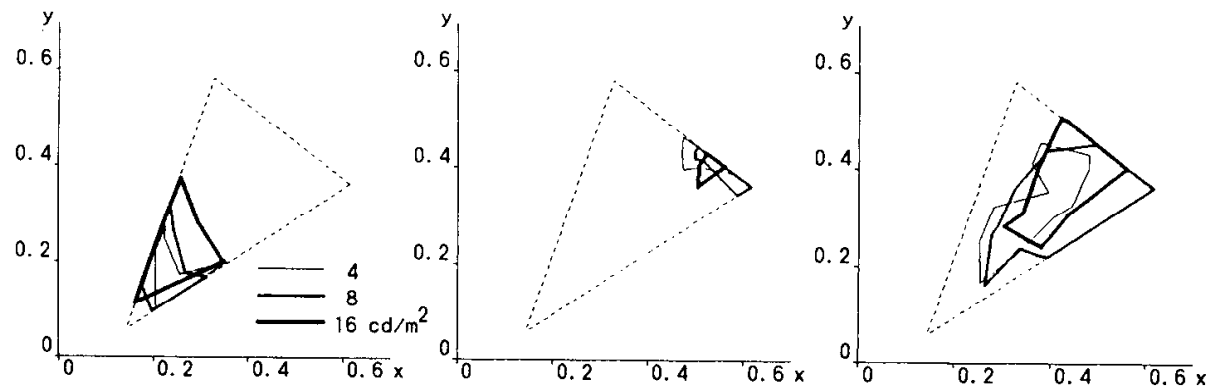

peak response
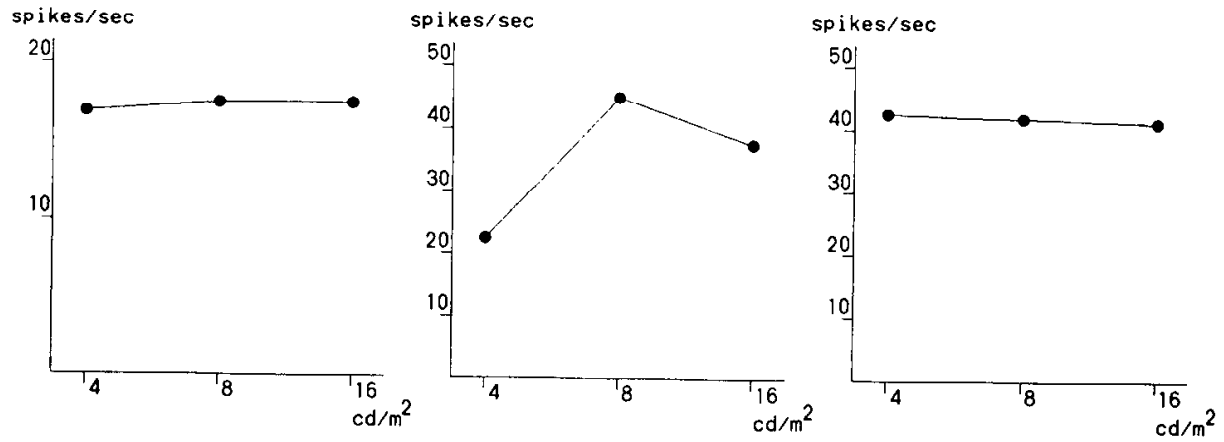

Figure 12. Effects of stimulus luminance on the ncural responses. $A$, Extent of the color space mapped at each luminance level. $B$, Typical effects of luminance in three cells. Each of the three columns represents a different cell. Top row, Effects of the luminance on the $50 \%$ color field. Color fields obtained by using stimuli with different range of luminance are superimposed. The range of luminance is within 0.1 $\log$ unit of $4 \mathrm{~cd} / \mathrm{m}^{2}$ for the color fields shown by the thinnest line, $0.1 \log$ unit of $8 \mathrm{~cd} / \mathrm{m}^{2}$ for that shown by the $m e$ dium line, and $0.1 \mathrm{log}$ unit of $16 \mathrm{~cd} / \mathrm{m}^{2}$ for that shown by the thickest line. The broken line indicates the extent of the color space mapped at the $8 \mathrm{~cd} / \mathrm{m}^{2}$ level. Middle row, Effects of the luminance on the $75 \%$ color field. Bottom row, Effects of the luminance on the maximum response. The abscissa indicates the luminance of the stimulus; the ordinate indicates the magnitude of the maximum response obtained at each luminance level. Color index of the cell 701895 is 0.98 at $4 \mathrm{~cd} / \mathrm{m}^{2}$ level, 1.0 at $8 \mathrm{~cd} / \overline{\mathrm{m}}^{2}$ level, and 0.82 at $16 \mathrm{~cd} / \mathrm{m}^{2}$ level. That of the cell 713892 is 1.22 , 1.18 , and 1.12 , and that of the cell 714893 is $0.63,0.54$, and 0.62 , respectively.
8 cclls wcrc like those in Figure $13 A, 10$ cells were like those in $B, 8$ cells were like those in $C$, and 4 cells were like those in $D$. The remaining cell had a trough followed by a peak in response with the increase in the stimulus size and was not classified into any of the above four types.

\section{Discussion}

We have studied the color selectivity of neurons in IT cortex of awake monkeys and found that many neurons selectively responded to some colors but not to others. To quantify the color selectivity of each neuron, we have used the CIE 1931 standard colorimetric system to represent the color of the stimuli used, and we mapped the responses of each neuron on the CIE color space. By using this system, we were able to test the responses to varying hue and saturation systematically. Also, this facilitated the comparison between the neural representation of color and our color perception of the stimulus. Although this system was developed on the basis of human psychophysical 
Figure 13. Effects of stimulus size on the responses of color-selective cells. In each drawing, the abscissa is the logarithm of the stimulus size defined as the square root of the area of the stimulus; the ordinate is the response that is normalized to $100 \%$ at the maximum response. Four different types of the effects are shown in $A-D$, respectively. Results from five different cells are superimposed in $A$ and $B$, three cells in $C$, and four cells in $D$. In $A$, cells preferred larger stimulus. In $B$, maximum response was obtained at some size, and the response became weaker either for larger or smaller stimuli. In $C$, cells preferred smaller stimulus. In $D$, the effect of the size was not clear.
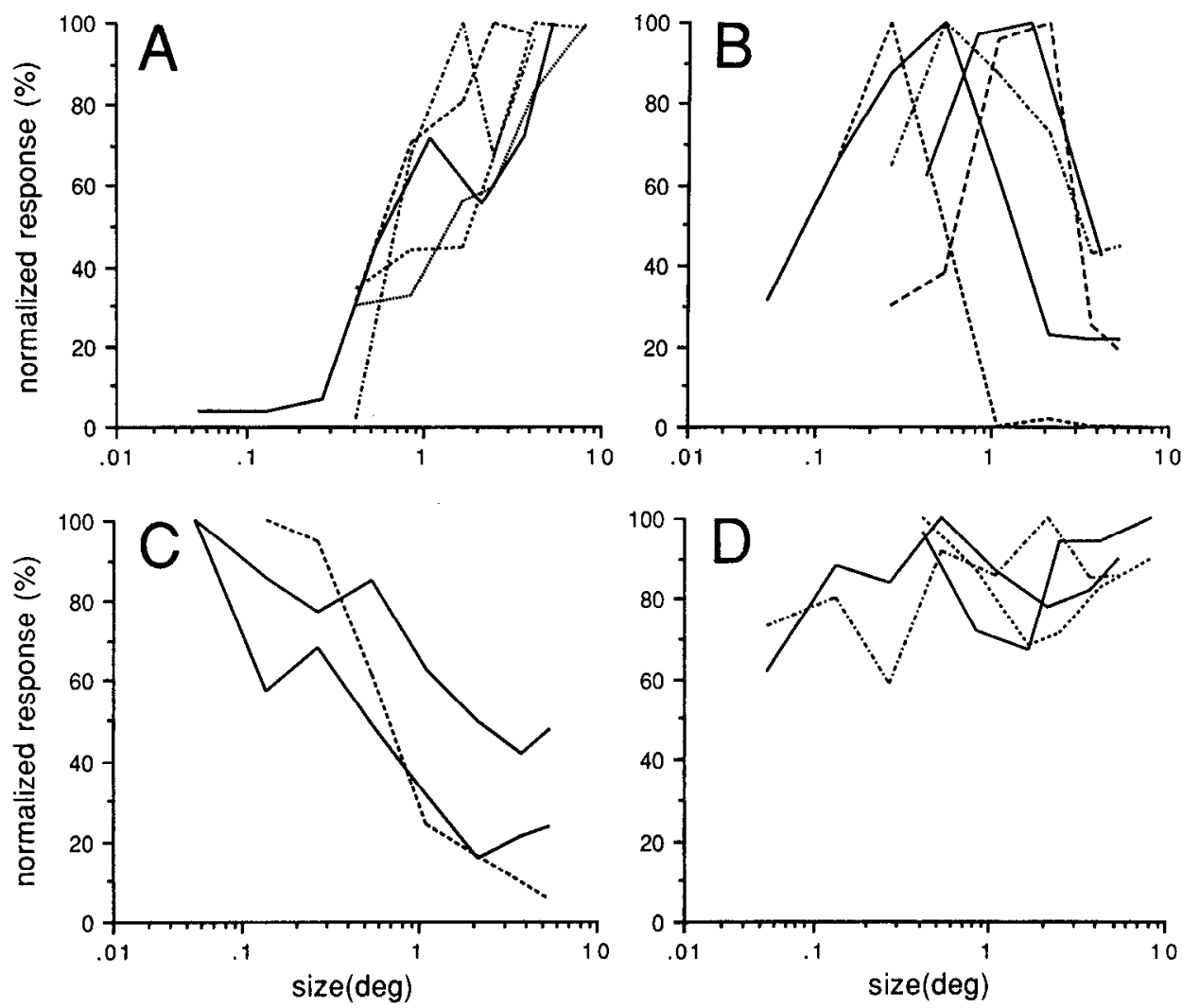

experiments, it is reasonable to use this system in the present experiments because humans and macaque monkeys are known to have very similar trichromatic color vision. This is shown by several kinds of experiments including the measurements of spectral sensitivities of three types of cones (Marks et al., 1964; Bowmaker and Dartnall, 1980; Bowmaker et al., 1980; Baylor et al., 1987; Schnapf et al., 1987), behavioral measurements such as the wavelength discrimination, saturation discrimination, and Rayleigh matching (De Valois et al., 1974; Oyama et al., 1979), and the categorization of color (Sandell et al., 1979).

In most previous studies of the primate visual system, color selectivity of a neuron was tested using monochromatic stimuli and was described as either the spectral sensitivity or as responses to isoluminant stimuli at different wavelengths. Derrington et al. (1984) studied the chromatic properties of neurons in the monkey LGN by examining responses to stimuli that were defined within a color space. More recently, Lennie et al. (1990) examined the chromatic properties of V1 neurons using the same method. They modulated the color and the luminance of the stimuli in certain directions in the color space and examined the relation between the direction of modulation and the magnitude of the response. The color space used by these investigators and the CIE color space used in the prescnt study are related by a linear transformation. The use of a color space offers several advantages over a spectrum, in particular by incorporating additional dimensions that may. be equally important for discrimination of surfaces in the environment.

In the following sections, we will consider our present results of color sensitivities of IT neurons first in relation to those reported in previous studies of IT and then with respect to neurons in the preceding stages in the extrastriate visual cortex.
Several studies have reported the existence of IT neurons sensitive to color (Gross et al., 1972; Mikami and Kubota, 1980; Fuster and Jervey, 1982; Desimone et al., 1984; Fuster, 1990). We found that a large majority of cells that were responsive to simple visual stimuli used in our experiments were sensitive to color at least to some degree. Incidence of color-sensitive neurons was about $66 \%$ of the neurons responsive to simple visual stimuli during the general survey, and it exceeded $70 \%$ of the cells recorded from guide tubes implanted into selected areas. These incidences are higher than those reported in the previous studies in IT cortex. The incidence of color-selective neurons among the neurons that were tested for color selectivity ranged from $9 \%$ (Desimone et al., 1984) to $48 \%$ (Gross et al., 1972). This difference is likely to stem in part from differences in criteria for color selectivity. It has been pointed out that the estimate of the proportion of color-selective cells can vary greatly depending on the criteria (Schein and Desimone, 1990). Another potential source of difference is that previous studies used fewer colors to study color preferences. As a result, each cell was less likely to be tested with its preferred and nonpreferred colors, thus yielding smaller difference between the responses to colors tested. There are two other problems we should point out about the incidence of the color-selective neurons in IT cortex. One problem is a possible regional difference in the concentration of the color-selective neurons. In one monkey, we found that the color-selective neurons were concentrated in regions slightly lateral to the anterior middle temporal sulcus. Recently, Sato and Kawamura (1990) have reported that the distributions of cells selectively responsive to visual patterns or color spots were different in area TE. They found that pattern-sensitive cells were more frequently observed in the dorsal part of TE (including 


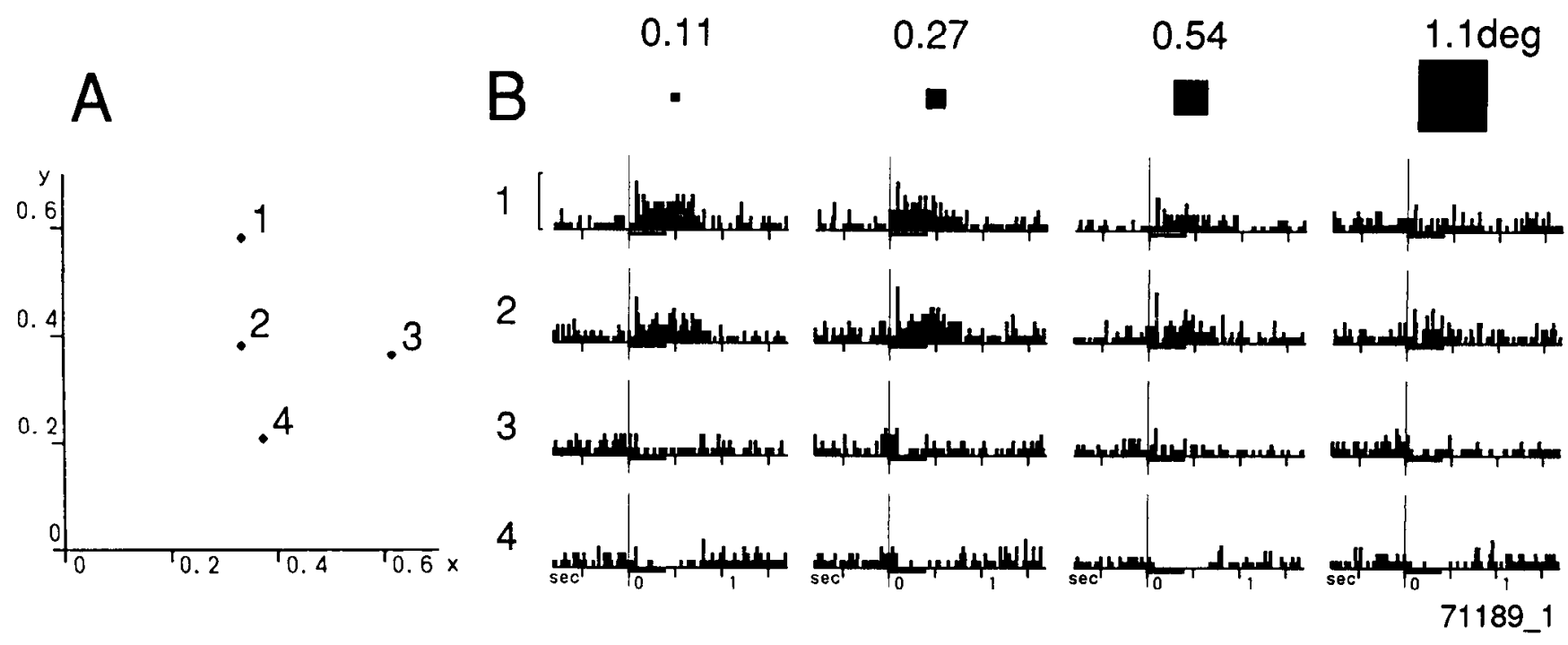

Figure 14. An example of a color-selective neuron that showed size preference. This is the same neuron as shown in Figures $6 A$ and $7 A$. Responses to four different color stimuli with four different sizes are shown. $A$, Chromaticity coordinates of the four color stimuli. $B$, In each column, histograms show responses to four color stimuli with the same size. Numbers by each row represent color and correspond to those in $A$. Different columns are for different stimulus sizes. Numbers at the top of each column indicate the square root of the area of the stimulus. The shape of the stimulus was square. Other conventions for histograms are as in Figure 3. Note that color preference does not depend on the size of the stimulus but the magnitude of the response gradually decreased with the increase of the stimulus size.

the lower bank of the STS and the adjacent IT gyrus) but colorsensitive cells were observed much more frequently in the ventral region. Such regional difference with regard to the properties of neurons together with some bias of the recording sites may account for the differences in the incidence of color-selective neurons reported in the various studies. Another problem concerning the estimate of the proportion of color-selective IT neurons is that some are sensitive to the shape as well as to the color of the stimulus (Desimone et al., 1984; Komatsu et al., 1991; Tanaka et al., 1991). During the general survey, we failed to drive many neurons using simple geometrical shapcs. It might be possible that some of these neurons were sensitive to color of more complex patterns.

Besides confirming the presence of color-selective neurons in IT cortex, the present study uncovered several basic properties of color-selective IT neurons that will be summarized here. Using a mapping of the responses in the color space, we found that the effective colors for each color-selective cell were clustered in one or more regions in the color space. We called such responsive regions in the color space "color fields." Color fields of most cells (about $80 \%$ ) consisted of a single continuous region with a single peak. In other cells, color fields had multiple peaks or separate responsive regions. The location, shape, and size of the color field varied from cell to cell. For a majority of cells, the most sensitive color was at or close to the edge of the color space examined; in other words, these cells preferred saturated colors. Preferred hue of these cells differed from cell to cell. Only a minority of cells responded selectively to colors with low saturation. The preferred color of such cells was in all cases desaturated purple or red (pink). The $50 \%$ color fields of these color-selective IT neurons collectively covered the entire color space examined, but there was a tendency for more color-sensitive cells to be less sensitive to white/gray and desaturated cyans. The extent and the location of the color field were largely independent of the luminance of the stimuli used in the exper- iments. Finally, many color-selective IT neurons were sensitive to the size of the stimulus.

Because characterization of color sensitivity was not the primary objective in previous studies of IT cortex, we were able to find very few descriptions related to the questions addressed here. One exception is the study by Fuster and Jervey (1982). They tested the activities of IT neurons during a delayed matchto-sample task using red and green stimuli in all cases and yellow and blue in some cases. They found that the magnitudes of the responses to sample stimuli were more closely correlated between red and yellow stimuli or green and blue stimuli than between other pairs of colors. They called cells that preferred red and yellow stimuli "warm cells" and those that preferred green and blue "cold cells." In the present experiments, we found that most cells have single continuous color field and that many have color fields along the edge of the color space. Therefore, their findings seem in part to be explained by ours because red and yellow or green and blue occupy adjacent regions along the edge of the color space. However, yellow and green are also adjacent to each other in the color space, and in fact we found cells that responded to both green and yellow stimuli (such as the cell shown in Fig. 7A). Furthermore, few color-selective cells in our sample responded to both green and blue strongly. One of the possible explanations for such discrepancies is that Fuster and Jervey used a more saturated green than we did. The distance between green and yellow stimuli along the edge of the color spacc would therefore have been larger, and the distance between green and blue stimuli would have been smaller.

Several studies have shown that lesion of IT cortex produces a deficit in hue discrimination (see Gross, 1973; Dean, 1976, 1982). Dean (1979) found that monkeys with IT lesions had a marked deficit in hue discrimination trained before surgery, but that with practice the threshold for hue discrimination improved to a level indistinguishable from normal monkeys. He suggested that IT cortex plays an important role in the hue categorization 
in normal monkeys, but that hue discrimination can nevertheless be accomplished without IT cortex. Obviously, information about stimulus hue exists in the activity of the color-sensitive cells in the various structures preceding IT cortex. Monkeys with an IT lesion might use this information. These results of the lesion studies can be interpreted in two ways in relation with the properties of color-selective neurons in IT cortex. The first possibility is that if IT neurons are tuned to smaller ranges of hues than earlier stages of color processing, IT cortex might play a special role in the identification of hue in normal animals. Another possibility is that the sharpness of the color selectivity is not relevant and that an attentional or associative mechanism of IT cortex is responsible for the deficit. Obviously, we do not have any direct evidence supporting either of the above two possibilities. Several studies have indicated modulation of neuronal activities in IT cortex by attention (Gross et al., 1979; Richmond et al., 1983; Moran and Desimone, 1985; Richmond and Sato, 1987; Sato, 1988) or by short-term memory (Fuster and Jervey, 1981, 1982; Miyashita and Chang, 1988). These findings seem more consistent with the latter possibility. In the following section, we will consider the properties of color-selective IT neurons in relation with color-selective neurons in other extrastriate visual areas.

Visual information from the striate cortex is relayed by several areas in the extrastriate cortex including areas V2 and V4 before reaching IT cortex (see Van Essen, 1985). It is now established that these extrastriate areas transfer both form and color information (see Maunsell and Newsome, 1987; DeYoe and Van Essen, 1988). The present study has shown that IT cortex is not an exception among the areas in the "form-color" pathway. Previous electrophysiological studies in IT cortex have indicated that this area is significantly involved in the processing of form information. Our study indicates that many cells in this area encode color information. In several important aspects, properties of color-selective neurons in IT cortex are similar to those in the preceding extrastriate areas. In each area, the degree of color selectivity ranges continuously from very low to very high, and there is no absolute distinction between the population of color-selective cells and that of non-color-selective cells (Burkhalter and Van Fssen, 1986; Shein and Desimone, 1990). With regard to the sharpness of the color selectivity, it is not possible to make a quantitative comparison between the present results and those obtained in other areas because most of such works were done using monochromatic lights. Several studies have shown that spectral bandwidth of the color-selective neurons is remarkably constant from the retinal ganglion cells through area V4 neurons (de Monasterio and Schein, 1982; Burkhalter and Van Essen, 1986; Shein and Desimone, 1990). Mean half-bandwidths of the spectral response curves are about $20-30 \mathrm{~nm}$ in each area. If we compare such bandwidth with the color naming of the spectrum (e.g., Kelly, 1943), it is evident that cells usually respond to some range of hues that are perceptually distinguished. This is also true in the present study, because color fields of IT neurons usually extended to more than one hue. In this sense, we cannot find any reason to say that the color selectivity in IT cortex is sharper or broader than other extrastriate areas.

In area V4, Schein and Desimone (1990) reported about 30\% of the cells had spectral-response curves with two peaks. It is also reported that some of area VP neurons also have two peaks in their spectral-response curves (Burkhalter and Van Essen, 1986), and that some V1 neurons prefer more than one spectral region (Lennie et al., 1990). It is likely that these cells have color fields that consisted of separate regions in the color space. In the present study, about $20 \%$ of the color-selective neurons had color fields that consisted of multiple peaks or separate regions. The proportions of cells with such complex color selectivity in area V4 and IT cortex are similar, and this provides further support for the idea that the color-selective IT neurons share the common characteristics with the preceding areas.

In the present study, some of the IT neurons (11\% of the color-selective neurons) responded selectively to colors with low saturation. Neurons also exist in areas VP and V4 that responded better to white than to any color. The proportion of such cells as counted from previously published figures (for VP, Fig. 12 of Burkhalter and Van Essen, 1986; for V4, Fig. 9 of Schein and Desimone, 1990) was 27\% (22 of 81$)$ in VP and $17 \%(11$ of 66) in V4. Each of these areas has cells particularly sensitive to low-saturation stimuli. What we are interested in is whether such cells in areas VP and V4 are most sensitive to white or to some other desaturated colors. In IT cortex, none of the highly color-selective neurons were most sensitive at the white point. Instead, color fields of the cells that preferred low saturation always centered at desaturated purple or red.

A major difference between neurons in IT cortex and those in the preceding areas is the size of their receptive fields. IT neurons have much larger receptive fields than those in area V4, and their receptive fields usually include parts of both visual hemifields. Many color-selective IT neurons were sensitive to the size of the stimulus, and some preferred stimuli about $10^{\circ}$ in size, well beyond the receptive field size of $\mathrm{V} 4$ neurons near the fovea. Because $10^{\circ}$ is the largest size we could generate, it is possible that these cells might have preferred even larger stimuli. It is reported that neurons in area V4 have large silent suppressive surrounds and do not respond well to homogeneous stimuli larger than the receptive field (Desimone et al., 1985; Schein and Desimone, 1990). A similar difference in size preference is reported for areas MT and MST in "motion" pathway. MT neurons have localized receptive fields with silent suppressive surrounds (Allman et al., 1985; K. Tanaka et al., 1986), whereas those in area MST tend to have large receptive fields and some prefer large field motion as a stimulus $(\mathrm{K}$. Tanaka et al., 1986; Komatsu and Wurtz, 1988). K. Tanaka et al. (1986) have suggested that the feedback projection from area MST to MT may be the source of silent suppressive surround seen in MT. It is possible to speculate a similar relation between IT cortex and area V4, so that the feedback projection from IT to V4 would be responsible for the silent suppressive surround in V4 neurons. It is suggested (Land, 1986; Hurlbert and Poggio, 1988; Schein and Desimone, 1990) that such silent suppressive surround plays an important role in color constancy (Zeki, 1980, 1983a,b). To accomplish color constancy of a given surface, a neural circuit must obtain spectral information from the large area surrounding the surface and subtract it from the spectral information obtained from the local region. The large receptive fields and the preference for large stimuli in IT neurons may be useful for this sort of computation.

\section{References}

Allman JM, Meizin F, McGuinness E (1985) Direction and velocityspecific responses from beyond the classical receptive field in the middle temporal visual area (MT). Perception 14:105-126.

Baylis GC, Rolls ET, Leonard CM (1985) Selectivity between faces in the responses of a population of neurons in the cortex in the superior temporal sulcus of the monkey. Brain Res 342:91-102. 
Baylor DA, Nunn BJ, Schnapf JL (1987) Spectral sensitivity of cone of the monkey Macaca fascicularis. J Physiol (Lond) 390:145-160.

Boussaoud D, Desimone R, Ungerleider LG (1991) Visual topography of area TEO in the macaque. J Comp Neurol 306:554-575.

Bowmaker JK, Dartnall HJA (1980) Visual pigments of rods and cones in a human retina. J Physiol (Lond) 298:501-511.

Bowmaker JK, Dartnall HJA, Mollon JD (1980) Microspectrophotometric demonstration of four classes of photoreceptor in an old world primate, Macaca fascicularis. J Physiol (Lond) 298:131-143.

Burkhalter A, Van Essen DC (1986) Processing of color, form, and disparity information in visual areas VP and V2 of ventral extrastriate cortex in the macaque monkey. J Neurosci 6:2327-2351.

Dean P (1976) Effects of inferotemporal lesions on the behavior of monkeys. Psychol Bull 83:41-71.

Dean P (1979) Visual cortex ablation and thresholds for successively presented stimuli in rhesus monkeys: II. Hue. Exp Brain Res 35:6983.

Dean P (1982) Visual behavior in monkeys with inferotemporal lesions. In: Analysis of visual behavior (Ingle DJ, Goodale MA, Mansfield RJW, eds), pp 587-628. Cambridge, MA: MIT Press.

de Monasterio FM, Schein SJ (1982) Spectral bandwidth of coloropponent cells of geniculocortical pathway of macaque monkeys. J Neurophysiol 47:214-224.

Derrington AM, Krauskopf J, Lennie P (1984) Chromatic mechanisms in lateral geniculate nucleus of macaque. J Physiol (Lond) 357:241265.

Desimone R, Gross CG (1979) Visual areas in the temporal cortex of the macaque. Brain Res 178:363-380.

Desimone R, Shein SJ (1987) Visual properties of neurons in area V4 of the macaque: sensitivity to stimulus form. J Neurophysiol 57:835868.

Desimone R, Fleming J, Gross CG (1980) Prestriate afferents to inferior temporal cortex: an HRP study. Brain Res 184:41-55.

Desimone R, Albright TD, Gross CG, Bruce C (1984) Stimulus-selective properties of inferior temporal neurons in the macaque. $J$ Neurosci 4:2051-2062.

Desimone R, Schein SJ, Moran J, Ungerleider LG (1985) Contour, color and shape analysis beyond the striate cortex. Vision Res 25: $441-452$.

De Valois RL, Morgan HC, Polson MC, Mead WR, Hull EM (1974) Psychophysical studies of monkey vision. I. Macaque luminosity and color vision tests. Vision Res 14:53-67.

DeYoe EA, Van Essen DC (1988) Concurrent processing streams in monkey visual cortex. Trends Neurosci 11:219-226.

Felleman DJ, Knierim JJ, Van Essen DC (1986) Multiple topographic and non-topographic subdivisions of the temporal lobe revealed by the connections of area V4 in macaques. Soc Neurosci Abstr 12:1182.

Fuster JM (1990) Inferotemporal units in selective visual attention and short-term memory. J Neurophysiol 64:681-697.

Fuster JM, Jervey JP (1981) Inferotemporal neurons distinguish and retain behaviorally relevant features of visual stimuli. Science 212 : 952-955.

Fuster JM, Jervey JP (1982) Neuronal firing in the inferotemporal cortex of the monkey in a visual memory task. J Neurosci 2:361375.

Gross CG (1973) Visual functions of inferotemporal cortex. In: Handbook of sensory physiology, Vol 7, Pt 3B, Central processing of visual information (Jung R, ed), pp 451-482. Berlin: Springer.

Gross CG, Rocha-Miranda CE, Bender DB (1972) Visual properties of neurons in inferotemporal cortex of the macaque. J Neurophysiol 35:96-111.

Gross CG, Bender DB, Gerstein GL (1979) Activity of inferior temporal neurons in behaving monkeys. Neuropsychologia 17:215-229.

Hurlbert AC, Poggio TA (1988) Synthesizing a color algorithm from examples. Science 239:482-485.

Judge SJ, Richmond BJ, Chu FC (1980) Implantation of magnetic search coils for measurement of eye position: an improved method. Vision Res 20:535-538.

Kelly KL (1943) Color designations for lights. J Opt Soc Am 33:627632.

Komatsu H, Wurtz RH (1988) Relation of cortical areas MT and MST to pursuit eye movements. I. Localization and visual properties of neurons. J Neurophysiol 60:580-603.

Komatsu H, Kaji S, Yamane S, Kawano K, Ideura Y (1989) Color selectivity of neurons in the inferotemporal cortex of the monkey. Soc Neurosci Abstr 15:120.

Komatsu H, Kaji S, Ideura Y, Yamane S (1990) Properties of colorselective neurons in the inferolemporal cortex of the awake monkey. Neurosci Res [Suppl] 11:145.

Komatsu H, Ideura Y, Kaji S, Yamane S (1991) Relation between color and shape selectivities of neurons in the inferotemporal cortex of the awake monkey. Neurosci Res [Suppl] 14:172.

Kuypers HGJM, Szwarcbart MK, Mishkin M, Rosvold HE (1965) Occipitotemporal corticocortical connections in the rhesus monkey. Exp Neurol 11:245-262.

Land EH (1986) An alternative technique for the computation of the designator in the retinex theory of color vision. Proc Natl Acad Sci USA 83:3078-3080.

Lennie P, Krauskopf J, Sclar G (1990) Chromatic mechanisms in striate cortex of macaque. J Neurosci 10:649-669.

Marks WB, Dobelle WH, MacNichol EF (1964) Visual pigments of single primate cones. Science 143:1181-1183.

Maunsell JHR, Newsome WT (1987) Visual processing in monkey extrastriate cortex. Annu Rev Neurosci 10:363-401.

Mikami A, Kubota K (1980) Inferotemporal neuron activities and color discrimination with delay. Brain Res 182:65-78.

Mishkin M, Ungerleider LG, Macko K (1983) Object vision and spatial vision: two cortical pathways. Trends Neurosci 6:414-417.

Miyashita Y, Chang HS (1988) Neuronal correlate of pictorial shortterm memory in the primate temporal cortex. Nature 331:68-70

Moran J, Desimone R (1985) Selective attention gates visual processing in the extrastriate cortex. Science 229:782-784.

Oyama T, Furusaka T, Kito T (1979) Color vision tests of Japanesc and rhesus monkeys. In: Current perspectives in primate biology (Taub DM, King FA, eds), pp 253-269. New York: Van Nostrand Reinhold.

Richmond BJ, Sato T (1987) Enhancement of inferior temporal neurons during visual discrimination. J Neurophysiol 58:1292-1306.

Richmond BJ, Wurtz RH, Sato T (1983) Visual responses of inferior temporal neurons in awake rhesus monkey. J Neurophysiol 50:14151432.

Richmond BJ, Optican LM, Podell M, Spitzer H (1987) Temporal encoding of two-dimensional patterns by single units in primate inferior temporal cortex. I. Response characteristics. J Neurophysiol 57:132-146.

Robinson DA (1963) A method of measuring eye movement using a scleral search coil in a magnctic ficld. IEEE Trans Biomed Eng 10: 137-145.

Rockland KS, Pandya DN (1979) Laminar origins and terminations of cortical connection of the occipital lobe in the rhesus monkey. Brain Res 179:3-20.

Rolls ET, Judge SJ, Sanghera MK (1977) Activity of neurones in the inferotemporal cortex of the alert monkey. Brain Res 130:229-238.

Sandell JH, Gross CG, Bornstein MH (1979) Color categories in macaques. J Comp Physiol Psychol 93:626-635.

Sato T (1988) Effects of attention and stimulus interaction on visual responses of inferior temporal neurons in macaque. $\mathbf{J}$ Neurophysiol 60:344-364.

Sato T, Kawamura T (1990) Distribution of cells in area TE selectively responsive to visual patterns or color spots during matching two visual stimuli at different locations. Jpn J Physiol 40:s238.

Sato T, Kawamura T, Iwai E (1980) Responsiveness of inferotemporal single units to visual pattern stimuli in monkeys performing discrimination. Exp Brain Res 38:313-319.

Schein SJ, Desimone R (1990) Spectral properties of V4 neurons in the macaque. J Neurosci 10:3369-3389.

Schein SJ, Marrocco RT, de Monasterio FM (1982) Is there a high concentration of color-selective cells in area V4 of monkey visual cortex? J Neurophysiol 47:193-213.

Schnapf JL, Kraft TW, Baylor DA (1987) Spectral sensitivity of human cone photoreceptor. Nature 325:439-441.

Schwartz EL, Desimone R, Albright TD, Gross CG (1983) Shape recognition and inferior temporal neurons. Proc Natl Acad Sci USA 80:5776-5778.

Tanaka K, Hikosaka K, Saito H, Yukic M, Fukada Y, Iwai E (1986) Analysis of local and wide-field movements in the superior temporal visual areas of the macaque monkey. J Neurosci 6:134-144.

Tanaka K, Saito H, Fukada Y, Moriya M (1990) Integration of form, texture, and color information in the inferotemporal cortex of the 
macaque. In: Vision, memory and temporal lobe (Iwai E, Mishkin M, eds), pp 101-109. New York: Elsevier.

Tanaka K, Saito H, Fukada Y, Moriya M (1991) Coding visual images of objects in the inferotemporal cortex of the macaque monkey. $\mathrm{J}$ Neurophysiol 66:170-189.

Tanaka M, Weber H, Creutzfeldt OD (1986) Visual properties and spatial distribution of neurons in the visual association area on the prelunate gyrus of the awake monkey. Exp Brain Res 65:11-37.

Ungerleider LG, Mishkin M (1982) Two cortical systems. In: Analysis of visual behavior (Ingle DJ, Goodale MA, Mansfield RJW, eds), pp 549-580. Cambridge, MA: MIT Press.

Van Essen DC (1985) Functional organization of primate visual cortex. In: Cerebral cortex, Vol 3 (Jones EG, Peters A, eds), pp 259-329. New York: Plenum.

Wurtz RH (1969) Visual receptive fields of striate cortex neurons in awake monkeys. J Neurophysiol 32:727-742.

Yamane S, Kaji S, Kawano K (1988) What facial features activate face neurons in the inferotemporal cortex of the monkey? Exp Brain Res 73:209-214.

Zeki SM (1973) Colour coding in rhesus monkey prestriate cortex. Brain Res 53:422-427.

Zeki SM (1977) Colour coding in the superior temporal sulcus of rhesus monkey visual cortex. Proc R Soc Lond [Biol] 197:195-223.

Zeki SM (1978) Uniformity and diversity of structure and function in rhesus monkey prestriate visual cortex. J Physiol (Lond) 277:273290.

Zeki SM (1980) The representation of colours in the cerebral cortex. Nature 284:412-418.

Zeki SM (1983a) Colour coding in the cerebral cortex: the reaction of cells in monkey visual cortex to wavelengths and colours. Neuroscience 9:741-765.

Zeki SM (1983b) Colour coding in the cerebral cortex: the responses of wavelength-selective and colour-coded cells in monkey visual cortex to changes in wavelength composition. Neuroscience 9:767-781. 